\title{
Diretrizes para o diagnóstico, classificação, profilaxia e tratamento da doença enxerto contra hospedeiro crônica
}

\author{
Guidelines for the diagnosis, classification, prophylaxis and treatment of chronic \\ graft-versus-host disease
}

\author{
Luis Fernando S. Bouzas ${ }^{1}$ \\ Marcia M. Silva ${ }^{2}$ \\ Rita de Cássia B. S. Tavares ${ }^{3}$ \\ Maria Cláudia R. Moreira ${ }^{3}$ \\ Maria Elvira P. Correa 4 \\ Vaneusa A. M. Funke \\ João Valdetaro ${ }^{6}$ \\ Mair P. Souza ${ }^{7}$ \\ Vergilio A. R. Colturato ${ }^{8}$ \\ Afonso C. Vigorito ${ }^{9}$ \\ Marcos A. Mauad \\ Lenira M. Q. Mauad ${ }^{10}$
}

\begin{abstract}
A falta de critérios diagnósticos padronizados, amplamente utilizados, pode comprometer tanto a avaliação real da incidência da doença contra hospedeiro crônica bem como a correlação de sua gravidade com a taxa de mortalidade pós-transplante. $\mathrm{Na}$ I Reunião de Diretrizes da Sociedade Brasileira de Transplante de Medula Óssea, realizada em junho de 2009, o Grupo de Estudos de DECH Brasil-Seattle (GEDECH), baseado na realidade dos Centros brasileiros, apresentou as recomendações para diagnóstico, classificação, profilaxia e tratamento da doença enxerto contra hospedeiro crônica propostas pelo National Institutes of Health. Estas propostas incluiram padronização das características utilizadas no diagnóstico e ferramentas para a pontuação dos órgãos envolvidos e avaliação global da gravidade a serem utilizados em estudos clínicos da doença enxerto contra hospedeiro crônica. Estes critérios são úteis para uma melhor análise da incidência desta doença, além de poder avaliar a gravidade do comprometimento de um órgão ou sítio envolvido e a influência na mortalidade tardia do transplante. A profilaxia e os tratamentos propostos para esta importante complicação dos transplantes de células-tronco hematopoéticas foram discutidos e graduados de acordo com niveis de evidência estabelecidos pelo National Institutes of Health. Rev. Bras. Hematol. Hemoter. 2010;32(Supl. 1):22-39.
\end{abstract}

Palavras-chave: Transplante de medula óssea; diagnóstico; classificação.

${ }^{I}$ Médico. Diretor do Centro de Transplante de Medula Óssea do Instituto Nacional de Câncer - Rio de Janeiro-RJ

${ }_{3}^{2}$ Médica dermatologista do Centro de Transplante de Medula Óssea do Instituto Nacional de Câncer - Rio de Janeiro-RJ

${ }^{3}$ Médica do Centro de Transplante de Medula Óssea do Instituto Nacional de Câncer - Rio de Janeiro-RJ

${ }^{4}$ Cirurgiã dentista da Unidade de Transplante de Células-Tronco Hematopoéticas do HC/Hemocentro da Universidade Estadual de Campinas-Unicamp - Campinas-SP.

${ }^{5}$ Médica responsável pelo Programa de Doença do Enxerto contra Hospedeiro e seguimento de longo prazo do Serviço de Transplante de Medula Óssea do Hospital de Clínicas da Universidade Federal do Paraná - Curitiba-PR.

${ }^{6}$ Médico oftalmologista do Centro de Transplante de Medula Óssea do Instituto Nacional de Câncer - Rio de Janeiro-RJ

Médico do Serviço de Transplante de Medula Óssea do Hemonúcleo Regional de Jaú/Fundação Amaral Carvalho - Jaú-SP.

${ }^{8}$ Médico. Coordenador do Serviço de Transplante de Medula Óssea do Hemonúcleo Regional de Jaú/Fundação Amaral Carvalho

Médico. Supervisor da Unidade de Transplante de Células-Tronco Hematopoéticas do HC/Hemocentro da Universidade Estadual de Campinas-Unicamp - Campinas-SP.

${ }^{10}$ Médica ginecologista do Serviço de Transplante de Medula Óssea do Hemonúcleo Regional de Jaúl Fundação Amaral Carvalho - Jaú-SP.

Centro de Transplante de Medula Óssea do Instituto Nacional de Câncer - Rio de Janeiro-RJ.

Unidade de Transplante de Células-Tronco Hematopoéticas do HC/Hemocentro da Unicamp - Campinas-SP

Serviço de Transplante de Medula Óssea do Hospital de Clínicas da Universidade Federal do Paraná - Curitiba-PR

Serviço de Transplante de Medula Óssea do Hemonúcleo Regional de Jaúl Fundação Amaral Carvalho - Jaú-SP.

Correspondência: Luis Fernando da Silva Bouzas

Pça da Cruz Vermelha, 23, $7^{\circ}$ andar - Centro

20230-130 - Rio de Janeiro-RJ - Brasil

Tel.: (55 21) 2506-6215

E-mail:lbouzas@inca.gov.br

Doi: 10.1590/S1516-84842010005000029 


\section{Critérios para o diagnóstico e classificação da Doença Enxerto-contra-Hospedeiro Crônica}

A classificação atualmente em uso da doença enxertocontra-hospedeiro crônica (DECH-c) foi proposta em 1980, baseada em dados de vinte pacientes. A doença foi classificada como limitada (comprometimento localizado de pele e/ ou fígado) ou extensa (comprometimento generalizado de pele ou doença limitada associada ao comprometimento de outros órgãos). Este sistema foi desenvolvido primariamente para distinguir os pacientes que necessitariam ou não de imunossupressão sistêmica. Entretanto, ela não reproduzia ou previa a mortalidade tardia relacionada ao transplante. ${ }^{1}$

Estudos prévios identificaram os fatores de risco associados a um aumento da mortalidade associada ao transplante entre os pacientes com DECH-c. As variáveis identificadas incluíram o envolvimento de múltiplos órgãos ou locais, uma piora da performance status, plaquetopenia no momento do diagnóstico (contagem de plaquetas menor do que $100.000 / \mathrm{mL}$ ), aparecimento progressivo da DECH-c, bilirrubinas elevadas e envolvimento extenso de pele (maior do que $50 \%$ da superfície corpórea). ${ }^{2,3,4-7}$ Porém, os modelos prognósticos de sobrevida não auxiliam na avaliação da gravidade e extensão da DECH-c em um determinado período de tempo, não existe um consenso de definições ou medidas validadas de resposta do tratamento da DECH-c e, além do mais, o critério diagnóstico atual ${ }^{1}$ é baseado em avaliações subjetivas, dificultando as comparações dos resultados entre os diferentes estudos clínicos.

Portanto, a falta de critérios diagnósticos padronizados, amplamente utilizados, pode comprometer tanto a avaliação real da incidência da DECH-c bem como a correlação da gravidade da $\mathrm{DECH}-\mathrm{c}$ com a mortalidade.

Desta maneira, um grupo de trabalho do National Institutes of Health (NIH) desenvolveu um projeto para consenso dos critérios que deverão ser utilizados em estudos clínicos da DECH-c, ${ }^{8-13}$ padronizou as características utilizadas no diagnóstico e propôs meios para a pontuação dos órgãos envolvidos e avaliação global da gravidade. ${ }^{8}$ Estes critérios são úteis para uma melhor análise da incidência da DECH-c, além de poder avaliar a gravidade do comprometimento de um órgão, ou local, isolado, ou combinado, e a influência na mortalidade tardia do transplante. ${ }^{8}$

\section{Critérios para o diagnóstico da DECH-c ${ }^{8}$}

No passado, muitas manifestações da DECH que se apresentavam em torno de 100 dias após o transplante de células-tronco hematopoéticas (TCTH) eram arbitrariamente definidas como DECH-c, mesmo se estas manifestações clínicas fossem indistinguíveis da DECH aguda (DECH-a). Nas últimas duas décadas, os avanços na prática do TCTH alteraram profundamente a apresentação e a história natural, tanto da DECH-a, como da DECH-c, trazendo questionamentos quanto às definições. Pelo atual consenso ${ }^{8}$ do NHI, são as manifestações clínicas, e não o tempo de início dos sintomas após o TCTH, que determinam se clinicamente a DECH é aguda ou crônica. Pelo consenso do NIH, sinais e sintomas diagnósticos se referem àquelas manifestações que estabelecem a presença de DECH-c sem a necessidade de testes ou evidências de outros órgãos acometidos. Sinais e sintomas distintos se referem àquelas manifestações que não são comumente encontradas na DECH-a, mas não são consideradas suficientes para estabelecer um diagnóstico preciso de DECH-c sem outros testes ou envolvimento de outros órgãos. Outras características definem manifestações raras, controversas e não específicas de DECH-c que não podem ser utilizadas para firmar o diagnóstico de DECH-c. Sinais e sintomas comuns são observados tanto na DECH-a como na crônica.

As manifestações orgânicas específicas da DECH-c são apresentadas na Tabela $1 .^{8}$

O grupo de trabalho do NIH recomenda os seguintes critérios para o diagnóstico da $\mathrm{DECH}-\mathrm{c}^{8}$ :

- Distinção da DECH-a.

- Presença de pelo menos um sinal clínico diagnóstico da DECH-c, ou a presença de pelo menos uma manifestação distinta (não vista na $\mathrm{DECH}-\mathrm{a}$, mas não suficiente para ser considerada diagnóstica da DECH-c), confirmada por biópsia pertinente de acordo com critérios histopatológicos definidos (Tabela 2), testes laboratoriais, ou imagens radiológicas, no mesmo ou outro órgão.

- Exclusão de outros diagnósticos possíveis.

Um sistema de pontuação clínico (0-3) deve ser utilizado para a avaliação do envolvimento de órgãos ou locais, individualmente.

Uma avaliação global da gravidade (leve, moderada ou grave) deve ser realizada, utilizando a combinação das pontuações obtidas na avaliação individual, dos órgãos ou locais acometidos. $^{8}$

Pontuação clínica para avaliação dos órgãos ${ }^{8}$

Os órgãos considerados para a pontuação serão a pele, boca, olhos, trato gastrointestinal (TGI), fígado, pulmões, articulações e fáscias e o trato genital feminino. Cada órgão ou local receberá uma pontuação de $0-3$, com zero representando nenhum envolvimento, e três comprometimento grave. (Tabela 3)

\section{Diagnóstico diferencial entre DECH-a e DECH-c ${ }^{8}$}

Duas formas clínicas principais de DECH estão estabelecidas, cada qual com duas subcategorias. A DECH-a clássica (lesões máculo-papulosas, náusea, vômitos, anorexia, diarreia, íleo paralítico ou hepatite colestática) ocorre antes dos 100 dias após o TCTH ou DLI (sem sinais diagnósticos ou distintos de DECH-c) e a DECH-a tardia, persistente ou recorrente (alterações da DECH-a clássica, sem sinais diag- 
Tabela 1. Sinais e sintomas de DECH-c

\begin{tabular}{|c|c|c|c|c|}
\hline $\begin{array}{l}\text { Órgão ou } \\
\text { sistema }\end{array}$ & $\begin{array}{l}\text { Diagnóstico } \\
\text { (Suficiente para estabelecer } \\
\text { o diagnóstico de } \mathrm{DECH}-\mathrm{c} \text { ) }\end{array}$ & $\begin{array}{l}\text { Distinto } \\
\text { (visto na DECH-c, mas } \\
\text { insuficiente para estabelecer } \\
\text { sozinho o diagnóstico de } \\
\text { DECH-c) }\end{array}$ & Outras características & $\begin{array}{l}\text { Comuns } \\
\text { (vistos tanto na DECH-a } \\
\text { como crônica) }\end{array}$ \\
\hline Pele & $\begin{array}{l}\text { Poiquilodermia } \\
\text { Líquen-plano like } \\
\text { Alterações de Esclerose } \\
\text { Mórfea-like } \\
\text { Esclerose não móvel } \\
\text { Líquen escleroso }\end{array}$ & Despigmentação & $\begin{array}{l}\text { Alteração na sudorese } \\
\text { Idiose } \\
\text { Ceratose Pilar } \\
\text { Hipopigmentação } \\
\text { Hiperpigmentação }\end{array}$ & $\begin{array}{l}\text { Eritema } \\
\text { Lesões máculo-papulosas } \\
\text { Prurido }\end{array}$ \\
\hline Unhas & & $\begin{array}{l}\text { Distrofia } \\
\text { Estrias longitudinais } \\
\text { Unhas opacas, Onicólise } \\
\text { Perda das unhas }\end{array}$ & & \\
\hline Cabelos & & $\begin{array}{l}\text { Alopecia cicatrizante ou não } \\
\text { cicatrizante (após } \\
\text { a.quimioterapia) } \\
\text { Descamação com pápulas no } \\
\text { couro cabeludo }\end{array}$ & $\begin{array}{l}\text { Couro cabeludo com cabelos } \\
\text { escassos, ásperos } \\
\text { Canice precoce }\end{array}$ & \\
\hline Boca & $\begin{array}{l}\text { Like-plano like } \\
\text { Placas hiperceratóticas } \\
\text { Restrição na abertura da } \\
\text { boca pela esclerose }\end{array}$ & $\begin{array}{l}\text { Xerostomia } \\
\text { Mucocele } \\
\text { Mucocele } \\
\text { Atrofia da mucosa } \\
\text { Pseudomembranas } \\
\text { Úlceras }\end{array}$ & & $\begin{array}{l}\text { Gengivite } \\
\text { Mucosite } \\
\text { Eritema } \\
\text { Dor }\end{array}$ \\
\hline Olhos & & $\begin{array}{l}\text { Sensação de areia nos } \\
\text { olhos, ressecamento e dor } \\
\text { Conjuntivite cicatricial } \\
\text { Ceratoconjuntivite sicca } \\
\text { Áreas confluentes de } \\
\text { ceratopatia punctuada }\end{array}$ & $\begin{array}{l}\text { Fotofobia } \\
\text { Hiperpigmentação periorbitária } \\
\text { Blefarite(eritema ao redor } \\
\text { olhos com edema) }\end{array}$ & \\
\hline Genitália & $\begin{array}{l}\text { Like-plano like } \\
\text { Sinéquia e } \\
\text { estenose da vagina }\end{array}$ & $\begin{array}{l}\text { Erosões } \\
\text { Fissuras } \\
\text { Úlceras }\end{array}$ & & \\
\hline Trato GI & $\begin{array}{l}\text { Membranas no esôfago } \\
\text { Estreitamento ou estenose do } \\
\text { terço superior e médio do } \\
\text { esôfago }\end{array}$ & & $\begin{array}{l}\text { Insuficiência do pâncreas } \\
\text { exócrino }\end{array}$ & $\begin{array}{l}\text { Anorexia } \\
\text { Náusea; vômitos } \\
\text { Diarreia } \\
\text { Perda de peso; Déficit de } \\
\text { crescimento (crianças) }\end{array}$ \\
\hline Fígado & & & & $\begin{array}{l}\text { Bilirrubina total, fosfatase } \\
\text { alcalina }>2 \times \text { acima limite } \\
\text { normal } \\
\text { ALT e AST. }>2 \times \text { limite } \\
\text { normal }\end{array}$ \\
\hline Pulmão & $\begin{array}{l}\text { Bronquiolite obliterante } \\
\text { diagnosticada com biópsia } \\
\text { pulmonar }\end{array}$ & $\begin{array}{l}\text { Bronquiolite obliterante } \\
\text { diagnosticada com TFPs e } \\
\text { radiologia }\end{array}$ & & \\
\hline $\begin{array}{l}\text { Músculos, } \\
\text { fáscia e } \\
\text { articulações }\end{array}$ & $\begin{array}{l}\text { Fasciite } \\
\text { Articulações endurecidas ou } \\
\text { contratura secundária a } \\
\text { esclerose }\end{array}$ & Miosite ou polimiosite & $\begin{array}{l}\text { Edema } \\
\text { Cãimbras musculares } \\
\text { Artralgia ou artrite }\end{array}$ & \\
\hline $\begin{array}{l}\text { Hematopoético } \\
\text { e imune }\end{array}$ & & & $\begin{array}{l}\text { Trombocitopenia } \\
\text { Eosinofilia } \\
\text { Linfopenia } \\
\text { Hipo- ou } \\
\text { Autoanticorpos (AHAI e PTI) }\end{array}$ & \\
\hline Outros & & & $\begin{array}{l}\text { Derrame pericárdico e pleural } \\
\text { Asciite } \\
\text { Neuropatia periférica } \\
\text { Síndrome } \\
\text { Miastenia gravis } \\
\text { Cardíaco: anormalidade na } \\
\text { condução ou cardiomiopatia }\end{array}$ & \\
\hline
\end{tabular}

Em todos os casos, infecção, efeitos de drogas, malignidade. ou outras causas devem ser excluídas. Diagnóstico da DECH-c requer confirmação por radiologia ou biópsia (ou teste Schirmer para os olhos). ALT- aminotransferase alanina; AST- aminotransferase aspartase; BOOP - bronquiolite obliterante organizada com pneumonia; TFPs- testes de função pulmonar; AlHA- anemia hemolítica autoimune; PTI-púrpura trombocitopênica idiopática 
Tabela 2. Critérios Histopatológicos para DECH por órgãos 12

\begin{tabular}{|c|c|c|}
\hline Órgãos e Sistemas & $\begin{array}{l}\text { Critérios mínimos para } \\
\text { DECH ativa }\end{array}$ & Critério específico para DECH-C ${ }^{\star *}$ \\
\hline Pele, em qualquer etapa & $\begin{array}{l}\text { Apoptose na camada basal da epiderme ou } \\
\text { camada de malpighi } \pm \text { inflamação liquenoide } \\
\pm \text { mudança vacuolar }\end{array}$ & \\
\hline Líquen-plano like & & $\begin{array}{l}\text { Combinação de hipergranulose e acantose com alterações } \\
\text { liquenoides } \pm \text { siringite das unidades écrinas } \pm \text { paniculite }\end{array}$ \\
\hline Esclerose não móvel & & $\begin{array}{l}\text { Depósito de colágeno com espessamento da derme papilar ou } \\
\text { colagênese pandérmica } \pm \text { paniculite }\end{array}$ \\
\hline Esclerose tipo mórfea & & $\begin{array}{l}\text { Lesão localizada com predomínio de esclerose na derme reticular } \\
\text { inferior ou ao longo da borda derme-hipoderme } \pm \text { envolvimento da } \\
\text { epiderme e apêndices }\end{array}$ \\
\hline Fasciíte & & $\begin{array}{l}\text { Espessamento com fibrose do septo fascial com inflamação adjacente } \\
\pm \text { paniculite }\end{array}$ \\
\hline Fígado & $\begin{array}{l}\text { Pequenos ductos biliares dismórficos ou } \\
\text { destruídos } \pm \text { colestase, inflamação lobular } \\
\text { e/ou portal }\end{array}$ & $\begin{array}{l}\text { Ductopenia, fibrose portal e colestase crônica refletem a cronicidade, } \\
\text { mas não são específicos para DECH-c }\end{array}$ \\
\hline Gastrointestinal & $\begin{array}{l}\text { Critério de apoptose variável ( } \geq 1 \text { pedaço) } \\
\text { nas criptas }\end{array}$ & $\begin{array}{l}\text { Destruição das glândulas, ulceração ou fibrose submucosa refletem } \\
\text { doença de longa duração, mas não especificamente DECH-c }\end{array}$ \\
\hline Mucosa oral e conjuntiva & $\begin{array}{l}\text { Infiltração linfocítica da mucosa com } \\
\text { apoptose variável + }\end{array}$ & \\
\hline Glândula salivar ou lacrimal & & $\begin{array}{l}\text { Infiltração ou dano dos ductos intralobulares, fibroplasia do estroma } \\
\text { periductal e inflamação com destruição do tecido acinar+ }\end{array}$ \\
\hline Pulmão & & $\begin{array}{l}\text { Bronquiolite obliterante: denso infiltrado eosinofílico sob o epitélio } \\
\text { respiratório, resultando em completa obliteração fibrosa ou algum grau } \\
\text { de estreitamento do lúmen* }\end{array}$ \\
\hline
\end{tabular}

nósticos ou distintos de DECH-c) ocorre em torno dos 100 dias após o TCTH ou DLI (frequente após retirada da imunossupressão). A DECH-c clássica não apresenta características da DECH-a, e, na síndrome de sobreposição, as manifestações de DECH-a e crônica aparecem juntas.

$\mathrm{O}$ diagnóstico da $\mathrm{DECH}-\mathrm{c}$ também incluirá duas subcategorias: (1) DECH-c clássica, sem características da DECHa e sem limite de tempo; (2) síndrome de sobreposição nas quais as características da DECH-a e crônica aparecem concomitantemente, sem limite de tempo. Na ausência de confirmação histológica, ou de sinais ou sintomas clínicos da DECHc, a persistência, recorrência, ou novo aparecimento de alterações na pele, TGI ou fígado serão classificados como $\mathrm{DECH}-\mathrm{a}$, independentemente do tempo após o transplante.

O diagnóstico diferencial entre DECH-a e DECH-c está representado na Tabela 4.

\section{Pontuação global da DECH-c c $^{8}$}

A avaliação global da gravidade é baseada no número de órgãos ou locais envolvidos e no grau de envolvimento de cada órgão afetado. Os pacientes são considerados com diagnóstico de DECH-c leve quando apenas um ou dois órgãos ou locais (exceto os pulmões) forem afetados, sem dano funcional clinicamente significante (pontuação máxima de 1 em todos os órgãos ou locais). O diagnóstico de DECH-c moderada é considerado quando (1) pelo menos um órgão ou local apresentar comprometimento clínico significante, porém sem dano maior (pontuação máxima de 2 em qualquer órgão ou local afetado), ou (2) três ou mais órgãos ou locais sem prejuízo funcional clinicamente significante (pontuação máxima de 1 em todos os órgãos ou locais afetados). Pontuação de 1 nos pulmões também é considerada moderada. DECH-c grave indica dano maior (pontuação de 3 em qualquer órgão ou local). Pontuação maior ou igual a 2 nos pulmões será considerada grave. A pontuação global da DECH-c está representada na Tabela 5.

\section{Indicação de tratamento sistêmico ${ }^{8}$}

A DECH-c leve pode ser tratada somente com medicamentos tópicos. Entretanto, os pacientes com DECH-c que envolve três ou mais órgãos, ou com pontuação de 2 ou mais em qualquer órgão, deverão ser considerados para o tratamento sistêmico. A presença de fatores de risco, e se a doença é maligna ou não maligna, poderá influenciar na decisão de iniciar, ou não, o tratamento sistêmico. O tratamento precoce sistêmico pode prevenir a progressão para uma DECH-c grave, enquanto as infecções poderão modificar as decisões em relação ao tempo e à intensidade do tratamento. (Tabela 6)

\section{Critérios de monitorização de resposta ao tratamento}

A falta de critérios de resposta bem estabelecidos é o maior obstáculo para medir a eficácia ao tratamento. O consenso do NIH estabeleceu critérios de resposta para DECHc e autoavaliação fornecida pelo paciente sobre o status da sua doença. 
Tabela 3. Pontuação clínica para avaliação dos órgãos envolvidos

\begin{tabular}{|c|c|c|c|c|}
\hline & Escore 1 & 2 & 3 & 4 \\
\hline $\begin{array}{l}\text { Performance } \\
\text { Pontuação } \\
\text { ( ) KPS ou LPS }\end{array}$ & $\begin{array}{l}\text { ( ) Assintomático ou } \\
\text { plenamente ativo } \\
\text { KPS ou LPS 100\%) }\end{array}$ & $\begin{array}{l}\text { () Sintomático, } \\
\text { ambulatorial, restrito } \\
\text { somente a atividades } \\
\text { mais ativas }\end{array}$ & $\begin{array}{l}\text { ( ) Sintomático, ambulatorial, } \\
\text { capaz de se cuidar, } \\
>50 \% \text { do tempo fora da } \\
\text { cama (KPS ou LPS } 60-70 \% \text { ) }\end{array}$ & $\begin{array}{l}\text { ( )Sintomático, se cuida com } \\
\text { limites, } \\
>50 \% \text { do tempo fora da cama } \\
\text { (KPS ou LPS }<60 \% \text { ) }\end{array}$ \\
\hline $\begin{array}{l}\text { Pele } \\
\text { Características clínicas } \\
\text { ( ) Lesões máculo-papulosas } \\
\text { () Líquen-plano like } \\
\text { () Ictiose } \\
\text { () Hiperpigmentação } \\
\text { () Hipopigmentação } \\
\text { () Ceratose folicular } \\
\text { ( ) Eritema } \\
\text { () Poiquilodermia } \\
\text { () Esclerose cutânea } \\
\text { () Prurido } \\
\text { () Envolvimento cabelos } \\
\text { () Envolvimento unhas } \\
\text { \% SC envolvida }\end{array}$ & ( ) Sem sintomas & $\begin{array}{l}\text { ( ) }<18 \% \text { ASC com } \\
\text { sinais da doença, } \\
\text { mas sem esclerose }\end{array}$ & $\begin{array}{l}\text { ( ) } 19-50 \% \text { SC ou } \\
\text { alterações de esclerose } \\
\text { superficial com } \\
\text { possibilidade de pinçamento }\end{array}$ & $\begin{array}{l}\text { ( ) }>50 \% \text { SC ou com alterações } \\
\text { de esclerose profunda sem } \\
\text { possibilidade de pinçamento ou } \\
\text { mobilização; ulceração ou } \\
\text { intenso prurido }\end{array}$ \\
\hline Boca & () Sem sintomas & $\begin{array}{l}\text { ( ) Sintomas leves } \\
\text { com sinais da doença, } \\
\text { mas sem limitação } \\
\text { significativa para a } \\
\text { ingestão oral }\end{array}$ & $\begin{array}{l}\text { ( ) Sintomas moderados } \\
\text { com sinais da doença } \\
\text { com limitação parcial } \\
\text { da ingestão }\end{array}$ & $\begin{array}{l}\text { ( ) Sintomas graves com } \\
\text { sinais da doença ao exame } \\
\text { com limitação maior da } \\
\text { ingestão oral }\end{array}$ \\
\hline $\begin{array}{l}\text { Olhos - Teste Shirmer }(\mathrm{mm}) \\
\text { () }>10 \\
\text { () } 6-10 \\
\text { () } \leq 5 \\
\text { () Não realizado }\end{array}$ & () Sem sintomas & $\begin{array}{l}\text { ( ) Sintomas de olho } \\
\text { seco leves não } \\
\text { afetando as AD (uso } \\
\text { de colírio <3x ao dia) } \\
\text { OU sinais de } \\
\text { ceratoconjuntivite } \\
\text { sicca assintomática }\end{array}$ & $\begin{array}{l}\text { ( ) Sintomas de olho seco } \\
\text { moderados afetando } \\
\text { parcialmente as } A D \text { (uso de } \\
\text { colírio }>3 x \text { ao dia ou plugue } \\
\text { no ducto lacrimal) sem } \\
\text { prejuízo da visão }\end{array}$ & $\begin{array}{l}\text { () Sintomas de olho seco graves } \\
\text { afetando significativamente as } \\
\text { AD (óculos ou lentes especiais } \\
\text { para aliviar a dor) ou } \\
\text { incapacidade de trabalhar } \\
\text { devido aos sintomas oculares } \\
\text { OU perda da visão causada por } \\
\text { ceratoconjuntivite sicca }\end{array}$ \\
\hline Trato GI & () Sem sintomas & $\begin{array}{l}\text { ( ) Sintomas como } \\
\text { disfagia, anorexia, } \\
\text { náusea, vômitos, dor } \\
\text { abdominal ou diarreia } \\
\text { sem perda significativa } \\
\text { de peso }(<5 \%)\end{array}$ & $\begin{array}{l}\text { ( ) Sintomas associados com } \\
\text { perda de peso leve a } \\
\text { moderada (5-15\%) }\end{array}$ & $\begin{array}{l}\text { ( ) Sintomas associados com } \\
\text { perda de peso significante, } \\
>15 \% \text {, necessitando de } \\
\text { suplementação nutricional para a } \\
\text { maioria das necessidades } \\
\text { calóricas ou dilatação esofágica }\end{array}$ \\
\hline Fígado & ( ) PFH normal & $\begin{array}{l}\text { ( ) Bilirrubina elevada, } \\
\text { AST ou ALT<2 X } \\
\text { valor normal }\end{array}$ & $\begin{array}{l}\text { () Bilirrubinas }>3 \mathrm{mg} / \mathrm{dl} \text { ou } \\
\text { bilirrubina, enzimas } 2-5 \mathrm{x} \\
\text { valores normais }\end{array}$ & $\begin{array}{l}\text { () Bilirrubinas ou enzimas }>5 x \\
\text { valores normais }\end{array}$ \\
\hline $\begin{array}{l}\text { Pulmão } \\
\text { ( ) FEV1 } \\
\text { ( ) DLCO }\end{array}$ & $\begin{array}{l}\text { () Sem sintomas } \\
\text { () Fev } 1>80 \% \text { ou } \\
\text { LFS }=2\end{array}$ & $\begin{array}{l}\text { () Sintomas leve } \\
\text { (dispneia após } \\
\text { subir escadas } \\
\text { () FEV1 60-79\% ou } \\
\text { LFS 3-5 }\end{array}$ & $\begin{array}{l}\text { ( ) Sintomas moderados } \\
\text { (dispneia após } \\
\text { caminhar no plano) } \\
\text { ( ) FEV140-59\% } \\
\text { ou LFS } 6-9\end{array}$ & $\begin{array}{l}\text { ( ) Sintomas graves (dispneia ao } \\
\text { repouso; necessidade de O2) } \\
\text { ( ) FEV1=39\% OU LFS 10-12 }\end{array}$ \\
\hline Articulações e Fáscia & ( ) Sem sintomas & $\begin{array}{l}\text { ( ) Enrijecimento leve } \\
\text { dos braços e pernas, } \\
\text { movimentos articulares } \\
\text { normais ou levemente } \\
\text { diminuídos E sem } \\
\text { afetar as AD }\end{array}$ & $\begin{array}{l}\text { ( ) Enrijecimento dos braços } \\
\text { e pernas OU contraturas de } \\
\text { articulações, eritema devido } \\
\text { à fasciitis, diminuição } \\
\text { moderada dos movimentos } \\
\text { articulares e limitação das } \\
\text { AD leve a moderada }\end{array}$ & $\begin{array}{l}\text { ( ) Contratura com diminuição } \\
\text { significativa dos movimentos } \\
\text { articulares e limitação } \\
\text { significativa das AD (incapaz de } \\
\text { amarrar sapatos, abotoar } \\
\text { camisas, vestir-se, etc.) }\end{array}$ \\
\hline $\begin{array}{l}\text { Trato Genital } \\
\text { ( ) Exame ginecológico } \\
\text { não obtido (pontuação } \\
\text { apenas de sintomas }\end{array}$ & ( ) Sem sintomas & $\begin{array}{l}\text { ( ) Sintomática com } \\
\text { sinais distintos leves } \\
\text { no exame e sem } \\
\text { repercussão no coito } \\
\text { e desconforto mínimo } \\
\text { no exame ginecológico }\end{array}$ & $\begin{array}{l}\text { ( ) Sintomática com sinais } \\
\text { distintos no exame e com } \\
\text { dispaurenia leve ou } \\
\text { desconforto no exame } \\
\text { ginecológico }\end{array}$ & $\begin{array}{l}\text { ( ) Sintomática com sinais } \\
\text { avançados (estenose, fusão dos } \\
\text { lábios ou ulceração grave) e dor } \\
\text { acentuada no coito ou } \\
\text { incapacidade de colocar o } \\
\text { espéculo vaginal }\end{array}$ \\
\hline
\end{tabular}

KPS- Status performance de Karnofsky; LPS- Status performance de Lansky; SC- superfície corporal; PFH- provas função hepática; ALT- aminotransferase alanina; AST- aminotransferase aspartato

Outros indicadores, manifestações clínicas ou complicações relacionadas a $\mathrm{DECHc}$ (checar todos que se aplicam e marque a pontuação de gravidade (0-3) baseada no impacto funcional em que é aplicável (nenhum-0; leve-1; moderado-2; grave-3) 
Estreitamento esofageano. Asciete (serosite)

Miastenia gravis

Polimiosite

Plaquetas < $100.000 \mathrm{ml}$

Derrame pleural ...

Eosinofilia $>500 \mathrm{ml}$.

Outros:

Tabela 4. Diagnóstico diferencial entre DECH-a e DECH-c

\begin{tabular}{|c|c|c|c|}
\hline Categoria & $\begin{array}{c}\text { Tempo de } \\
\text { aparecimento } \\
\text { dos sintomas } \\
\text { após o } \\
\text { TCTH ou DLI }\end{array}$ & $\begin{array}{l}\text { Presença de } \\
\text { características } \\
\text { da DECH-a }\end{array}$ & $\begin{array}{c}\text { Presença de } \\
\text { características } \\
\text { da DECH-c }\end{array}$ \\
\hline \multicolumn{4}{|l|}{ DECH-a } \\
\hline $\begin{array}{l}\text { Clássica } \\
\text { Persistente, } \\
\text { recorrente ou de } \\
\text { aparecimento tardio }\end{array}$ & $\begin{array}{l}<100 \text { dias } \\
>100 \text { dias }\end{array}$ & $\begin{array}{l}\text { sim } \\
\text { sim }\end{array}$ & $\begin{array}{l}\text { não } \\
\text { não }\end{array}$ \\
\hline \multicolumn{4}{|l|}{ DECH-C } \\
\hline Clássico & $\begin{array}{l}\text { sem limite } \\
\text { tempo }\end{array}$ & não & $\operatorname{sim}$ \\
\hline Sobreposição & $\begin{array}{c}\text { sem limite } \\
\text { tempo }\end{array}$ & $\operatorname{sim}$ & $\operatorname{sim}$ \\
\hline
\end{tabular}

Tabela 5. Avaliação global da DECH-c

Leve - sem prejuízo funcional significante

- Somente 1-2 órgãos (exceto pulmões)

- Pontuação máxima de 1

Moderado - prejuizo funcional significante, mas sem incapacidade maior

- 3 ou mais órgãos com pontuação máxima de 1

- 1 órgão com pontuação máxima de 2

- Pulmão com pontuação de 1

Grave - incapacidade maior

- Pontuação de 3 em qualquer órgão ou local

- Pulmão com pontuação de 2

A avaliação global substituiu a nomenclatura "limitado-extenso"

Tabela 6. Indicação para tratamento sistêmico

\begin{tabular}{ccc}
\hline $\begin{array}{c}\text { Gravidade } \\
\text { global }\end{array}$ & $\begin{array}{c}\text { Alto risco para } \\
\text { mortalidade* }\end{array}$ & $\begin{array}{c}\text { Tratamento } \\
\text { sistêmico }\end{array}$ \\
\hline Leve & Não & Não \\
Leve & Sim & Sim \\
Moderado & Não/Sim & Sim \\
Grave & Não/Sim & Sim
\end{tabular}

* Plaquetas < 100.000/ L ou recebendo corticoide no momento do diagnóstico da DECH

\# Deve ser pesado o benefício do efeito enxerto-versus-tumor e o risco da $\mathrm{DECH}$

\section{Medidas de avaliação realizadas pelo médico}

A. Sinais e sintomas em órgãos específicos

- pele: cálculo da superfície corporal acometida, medida do tamanho de úlceras e intensidade dos sintomas;
- olhos: teste de Schirmer sem anestesia e avaliação da intensidade dos sintomas;

- mucosa oral: utilização da escala-escore de Schubert para mucosite oral com graduação de $0-15$ e intensidade dos sintomas;

- parâmetros hematopoéticos: contagem de plaquetas e eosinófilos;

- gastrointestinal: avaliado por exame clínico com escala de gravidade de doença de $0-3$;

- função hepática através de exames laboratoriais;

- alterações respiratórias através do volume expiratório forçado no primeiro segundo e capacidade de difusão respiratória para monóxido de carbono ajustada para hemoglobina;

- para mulheres: sintomas vulvo-vaginais;

- sistema músculo-esquelético: avaliação da mobilidade das articulações por profissional treinado

B. Medidas objetivas da performance física

- força de preensão (através de dinamômetro hidráulico) e caminhada de dois minutos

\section{Escala de Karnofsky e Lansky (Tabela 7)}

\section{Autoavaliação pelo paciente}

Através de formulários que fornecem informações sobre o status físico e a qualidade de vida, na visão do paciente.

\section{Prevenção da DECH-c}

Em consequência da fisiopatogenia da DECH-c não ser ainda bem compreendida, a utilização de regimes profiláticos é bastante limitada. A ocorrência da DECH-a constitui-se num fator de risco reconhecido para a DECH-c e esforços têm sido direcionados para profilaxia da forma aguda. Ainda que regimes de condicionamento de intensidade reduzida tenham sido associados a uma menor incidência de DECH-a, o mesmo não ocorreu com a doença crônica. ${ }^{14}$

Blume e cols ${ }^{14}$ utilizaram no início da década de 80 um esquema de uso de corticosteroide estendido além da fase aguda pós-transplante. Foi observada menor incidência de DECH-c, porém sem confirmação em outros estudos (EIa).

O uso estendido de ciclosporina (CSA) para prevenção (6 meses x 24 meses) em estudo clínico prospectivo randomizado por Kansu e cols ${ }^{15}$ não se correlacionou com menor incidência de doença crônica no grupo com mais tempo de uso; além disso, as taxas de mortalidade relacionada ao transplante, sobrevida livre de doença e sobrevida global foram semelhantes (EIa).

Quando a talidomida foi adicionada ao esquema profilático de CSA/metotrexato (MTX), observou-se uma maior incidência da doença crônica com impacto negativo na sobrevida global, atribuída a um efeito negativo da talidomida no estabelecimento de tolerância imunológica ${ }^{16}$ (EIa) . 
Tabela 7. Avaliação da performance por Karnofsky (KPS)/ Lansky (LPS)

\begin{tabular}{|c|c|c|}
\hline \multicolumn{3}{|c|}{ Performance } \\
\hline Score & Lansky (LPS) (pacientes < 16 anos) & Lansky (LPS) (pacientes < 16 anos) \\
\hline 100 & Totalmente ativo, normal & Sem queixas; sem evidência de doença \\
\hline 90 & Restrições leves em atividades físicas vigorosas & Atividade normal; sinais ou sintomas da doença leves \\
\hline 80 & Ativo, mas cansa mais rápido & $\begin{array}{l}\text { Atividade normal com esforço; alguns sinais ou sintomas da } \\
\text { doença }\end{array}$ \\
\hline 70 & $\begin{array}{l}\text { Grandes restrições e tempo menor nas } \\
\text { atividades físicas }\end{array}$ & $\begin{array}{l}\text { Cuida-se; incapaz de exercer atividades normais ou de } \\
\text { fazer trabalho ativo }\end{array}$ \\
\hline 60 & $\begin{array}{l}\text { Em pé e caminhando, mas mínima atividade; ocupa-se } \\
\text { com atividades mais calmas }\end{array}$ & $\begin{array}{l}\text { Necessita de assistência ocasional, mas tem capacidade de se } \\
\text { cuidar para muitas necessidades pessoais }\end{array}$ \\
\hline 50 & $\begin{array}{l}\text { Veste-se, mas fica muito deitado durante o dia; } \\
\text { capaz de participar em todas as atividades calmas }\end{array}$ & $\begin{array}{l}\text { Necessita de assistência considerável e cuidados médicos } \\
\text { frequentes; atividades calmas }\end{array}$ \\
\hline 40 & Maior parte na cama; participa de atividades calmas & Incapacitado; necessita de cuidado e assistência especiais \\
\hline 30 & $\begin{array}{l}\text { Na cama; necessita de assistência mesmo para } \\
\text { atividades calmas }\end{array}$ & $\begin{array}{l}\text { Gravemente incapacitado; é indicada internação embora a } \\
\text { morte não seja iminente }\end{array}$ \\
\hline 20 & Dorme com frequência; atividades passivas & $\begin{array}{l}\text { Muito doente; necessária internação; necessário tratamento de } \\
\text { suporte ativo }\end{array}$ \\
\hline 10 & Sem atividade; não deixa a cama & Moribundo \\
\hline 0 & Não responsivo & Morto \\
\hline
\end{tabular}

Cutler e cols publicaram recentemente um regime de imunoprofilaxia utilizando a associação de sirolimus e tacrolimus, sem metotrexato, e obtiveram uma pega rápida, uma baixa incidência de doença do enxerto contra hospedeiro, mínima toxicidade relacionada ao procedimento e excelente sobrevida em pacientes que receberam transplantes aparentados e não aparentados. ${ }^{17}$

Recentemente observou-se um interesse renovado na depleção de linfócitos $\mathrm{T}$ in vivo, usando anticorpos policlonais, especialmente a globulina antitimocítica de coelho (ATG). Diversos estudos incorporaram ATG no esquema de condicionamento ou quando administrada logo após o transplante, reportando taxas de incidência de DECH-c menores no grupo tratado, com significância estatística. ${ }^{18-19}$ Bacigalupo e cols ${ }^{20}$ demonstraram um efeito adicional protetor pulmonar no grupo tratado, evidenciado por exames funcionais pulmonares melhores no seguimento desses pacientes.

A estratégia de depleção T com utilização de anticorpos monoclonais in vitro, como o anti-CD52, já tem sido utilizada primariamente para profilaxia de $\mathrm{DECHa}$, com menor impacto na incidência da forma crônica. ${ }^{21} \mathrm{~A}$ administração in vivo em um estudo prospectivo ${ }^{22}$ reportou um caso de DECH-c numa série de 43 pacientes submetidos a um esquema de condicionamento com fludarabina e melfalan, com infusão de Campath no D-8 ao D-4 (CIIa).

Existem evidências na literatura que postulam um papel do linfócito B na etiopatogenia da DECH-c, sustentando a utilização do anti CD20 (rituximabe) no tratamento da doença crônica extensa, mas seu uso preventivo ainda está em pesquisa, no momento, num estudo clínico conduzido pelo National Cancer Institute.

\section{Tratamento da DECH-c}

A DECH-c, embora esteja associada a menor taxa de recidiva, permanece como principal causa de morbimortalidade tardia em receptores de TCTH. ${ }^{4} \mathrm{O}$ frequente acometimento de vários órgãos e o quadro clínico pleomórfico desta condição determinam um manejo multidisciplinar, que inclui, além das especialidades médicas, acompanhamento nutricional, fisioterápico, psicológico, odontológico e social. ${ }^{11}$ (AIII).

\section{Tratamento da DECH-c leve}

A forma leve sintomática geralmente deve ser tratada apenas com agentes tópicos. Entretanto, a boa prática médica dita flexibilidade nesta recomendação, de vez que imunossupressão sistêmica precoce pode prevenir progressão para DECH-c grave. Nesta decisão devem ser incorporados dados como a doença de base (maligna ou não maligna) e seu status ao transplante, presença de fatores de alto risco para progressão de DECH (trombocitopenia, instalação progressiva da doença). ${ }^{8}$

O tratamento tópico da DECH-c leve de pele, boca, olhos e trato genital, bem como a tabela traduzida do sistema de codificação dos níveis de evidência para tratamento de DECH-c reportada pelo NIH, estão contidos no tópico de terapia adjuvante deste Consenso.

\section{Tratamento da DECH-c moderada e grave}

\section{Tratamento sistêmico inicial}

Os critérios definidos no consenso do NIH para tratamento sistêmico englobam: pontuação $>2$ em um órgão, acometimento de três ou mais órgãos e DECH-c leve com carac- 
terísticas de alto risco (plaquetometria $<100.000 / \mathrm{mm}^{3}$ e uso de imunossupressor ao diagnóstico de DECH-c). ${ }^{8}$

$\mathrm{O}$ tratamento padrão, há mais de vinte anos, tem sido a combinação de CSA (10mg/ $\mathrm{kg} /$ dia dividida em duas doses) e prednisona ( $1 \mathrm{mg} / \mathrm{kg} / \mathrm{dia})$ (BIa). ${ }^{23}$ Entretanto, estudo randomizado ${ }^{24}$ comparou este esquema com uso isolado de prednisona $1 \mathrm{mg} / \mathrm{kg} / \mathrm{dia}$, reportando resposta equivalente entre os grupos, com melhor sobrevida livre de recidiva no grupo da prednisona isolada em pacientes com plaquetometria $>$ $100.000 / \mathrm{mm}^{3}$ (AIa). O uso combinado de inibidores de calcineurina e corticoide deve ser reservado a pacientes trombocitopênicos ou com uso prévio prolongado de corticoide, já que a taxa de necrose avascular foi menor com esta associação (AIa). O desmame deve ser iniciado, se resposta ou manifestações estáveis, após duas semanas de tratamento, reduzindo a dose da prednisona em $25 \%$ a cada semana até atingir, em seis a oito semanas, a dose alvo de $1 \mathrm{mg} / \mathrm{kg}$ em dias alternados, que deve ser mantida por dois a três meses nos casos de resposta não completa, formas severas ou presença de fatores de risco. Em seguida, reduzir $10 \%$ a $20 \%$ por mês até a suspensão total em nove meses. Após sucesso neste desmame, outros imunossupressores devem ser reduzidos a cada duas ou quatro semanas, sequencialmente, até a retirada. Em caso de retorno de sinais da DECH durante o desmame, o retorno à dose anterior, especialmente do corticoide, pode controlar a reativação (AIIa). ${ }^{25}$

Este método de desmame do Fred Hutchinson Cancer Research Center (FHCRC) permite a manutenção da resposta inicial em 1/3 dos pacientes que não necessitaram de tratamento secundário em revisão publicada por Martin e cols. ${ }^{26}$ Estudos da Universidade de Minnesota ${ }^{6,27}$ mostram taxas de resposta entre 51\%-72\% em um ano, com DECH mais responsiva entre os transplantados com sangue de cordão quando comparados aos enxertos de doadores não aparentados adultos. A sobrevida global foi de 50\%-74\% em quatro anos, sendo a maioria das mortes por infecção, talvez devido ao uso prolongado de corticosteroides reportado nestas séries (IIa).

$\mathrm{O}$ uso de micofenolato mofetil (MMF) associado ao tratamento inicial foi avaliado em estudo duplo-cego randomizado, ${ }^{28}$ fechado em 2008, após análise de resposta (resolução de DECH-c) em 151 pacientes (23\% - grupo MMF vs $18 \%$ - controles, NS). A comparação da taxa de retirada de imunossupressão em dois anos também não mostrou evidência de benefício em associar o MMF ao esquema inicial para DECH-c (DIa). Ensaio randomizado europeu ainda analisa esta questão. ${ }^{25}$

Wang e cols ${ }^{29}$ reportaram $83 \%$ de resposta global na análise de 86 pacientes que receberam MTX em baixa dose associado a CSA e/ou outros imunossupressores como tratamento inicial de DECH-c. A maior taxa de respostas completas foi na pele $(80 \%)$, seguida pela do fígado $(52 \%)$. Toxicidade grau 3 ocorreu em três pacientes. Necessário estudo randomizado para confirmar os resultados (CIIa).
Talidomida foi testada em dois ensaios randomizados ${ }^{30,31}$ que não mostraram benefício na sua associação à prednisona e inibidor de calcineurina. Seu uso esteve associado a significativo aumento de efeitos adversos (EIa).

Terapia inicial combinada com hidroxicloroquina está sendo testada por Gilman e cols (Universidade da Carolina do Norte, EUA) em ensaio randomizado, duplo-cego, multicêntrico. ${ }^{23}$

Estudos recentes ${ }^{32,33}$ mostraram papel de corticosteroide inalatório associado a broncodilatador (budesonida formoterol) como terapia adjuvante no tratamento da DECH-c pulmonar (bronquiolite obliterante) .

\section{Tratamento de resgate}

Vários agentes têm sido testados em pacientes com DECH-c refratária ao corticoide em séries de casos com amostra heterogênea ou estudos pequenos de fase II, dificultando o estabelecimento de um esquema padrão de segunda linha. Os principais estão selecionados abaixo. (Tabela 8)

- Micofenolato mofetil (MMF) - pró-droga ácido micofenólico, interfere na síntese de purinas e produz efeito citostático nos linfócitos T e B. Vários estudos ${ }^{34-37}$ com taxas de resposta entre $46 \%-75 \%$ com a associação com prednisona e inibidores de calcineurina em adultos e crianças, alguns com taxas altas de infecções oportunistas ${ }^{35}$ (AIIa).

- Fotoférese extracorpórea (FEC) - baseada no efeito do 8-metoxipsoraleno e da radiação ultravioleta A nos linfócitos coletados por aférese e reinfundidos ao paciente, o que induz a apoptose de linfócitos, alterações na função das células dendríticas, ativação de células T regulatórias, aumento da produção de IL-10 e outras citocinas imunossupressoras, favorecendo a anergia de células T. Flowers e cols, ${ }^{38} \mathrm{em}$ estudo randomizado, multicêntrico $(\mathrm{N}=99)$, reportaram melhora significativa do escore cutâneo (25\%) no grupo com FEC e aumento significativo da taxa de pacientes com redução $\geq$ $50 \%$ na dose de prednisona quando comparado ao grupo só com imunossupressão oral. Vários estudos ${ }^{39-41}$ mostram taxas de resposta global entre $56 \%$ e $70 \%$ e maior frequência de resposta na pele e mucosa oral (AIa) seguida pelo fígado (BIa), intestino e pulmão (CIIa).

- Tacrolimo - inibe a ativação de linfócito T pela ligação com FKBP-12 e previne a síntese de IL-2 e linfocinas essenciais na função do linfócito T. O grupo de Seattle ${ }^{42}$ publicou uma taxa de $21 \%$ de resposta, $\mathrm{N}=39$, com duração média do uso de tacrolimus de nove meses e $64 \%$ de sobrevida em três anos. Outros estudos, como o de Tzakis e cols, ${ }^{43}$ mostraram melhor taxa de resposta $(35 \%)$, porém com seguimento máximo de oito meses (BIIa).

- Sirolimo - antibiótico macrocíclico com propriedades imunossupressora, antitumoral e antifúngica. Inibe a ativação de células $\mathrm{T}$ e $\mathrm{B}$ através de citocinas, que, por sua vez, inibem progressão do ciclo celular e proliferação celular. Couriel e cols, ${ }^{44} \mathrm{em}$ ensaio fase II, testaram em 35 pacientes 
a combinação de sirolimus com tacrolimus e metilprednisona, com resposta global de $63 \%$ (maiores respostas na oral, gastrointestinal e cutânea). Outros estudos, ${ }^{45,46} \mathrm{com}$ tamanho de amostra que variou de 16 a 47, reportaram respostas de $94 \%$ e $81 \%$, respectivamente. Principal toxicidade descrita em todos estes estudos foi microangiopatia trombótica, provavelmente secundária a nível sérico alto de sirolimus, que potencializa a toxicidade vascular dos inibidores de calcineurina. Monitoração cuidadosa dos níveis de ambos os agentes pode prevenir a complicação. A indisponibilidade da droga em vários centros brasileiros é fator limitante (BIIa).

- Rituximabe - $\mathrm{o}$ anticorpo monoclonal anti-CD20 quimérico tem sido testado com intuito de depletar células B autorreativas e, no contexto alogênico, parece atuar seletivamente sobre a produção recorrente de anticorpos contra antígenos de histocompatibilidade menores ligados a DECHc, por exemplo, codificados com cromossomo Y. Cutler e cols ${ }^{47}$ testaram em ensaio fase I/II o anticorpo em 21 pacientes, com ciclos de $375 \mathrm{mg} / \mathrm{m}^{2} / \mathrm{semana}$ por quatro semanas, com intervalos de oito semanas. Taxa de resposta global de $70 \%$ nos vinte avaliáveis, limitada aos pacientes com DECH cutânea e músculo-esquelética. Já o grupo italiano ${ }^{48}$ reportou, em estudo multicêntrico retrospectivo, com resposta global de $65 \%$, e observação de respostas dose acumulativa dependentes em órgãos como boca (48\%), olhos (43\%), pulmão (38\%) e fígado (25\%). Este tratamento pode determinar impacto na qualidade de vida dos pacientes com forma esclerodermoide da doença (BIIa).

- Pentostatina - análogo nucleosídeo, que inibe a adenosina deaminase (ADA), que mostrou eficácia em estudo fase II, com 58 pacientes refratários e bastante tratados, publicado por Jacobsohn. ${ }^{49}$ A dose foi de $4 \mathrm{mg} / \mathrm{m}^{2}$ IV quinzenal com total de 12 doses. Resposta objetiva em $55 \%$, especialmente observada em lesões escleróticas, fasciíte e boca (CIIa).

Tabela 8. Agentes secundários na terapia da DECH-c

\begin{tabular}{|c|c|c|c|c|}
\hline Agente & $\begin{array}{l}\text { Taxas de resposta } \\
\text { observadas }\end{array}$ & $\begin{array}{c}\text { Taxas de resposta orgânica } \\
\text { específica (RC+RP) }\end{array}$ & Efeitos colaterais & $\begin{array}{l}\text { Sobrevida } \\
\text { global }\end{array}$ \\
\hline \multicolumn{5}{|l|}{ Drogas mais utilizadas } \\
\hline $\begin{array}{l}\text { MMF } \\
\text { (CELLCEPT) }\end{array}$ & $\begin{array}{l}46-75 \% \text { taxa de } \\
\text { resposta }(n=21-26)\end{array}$ & $\begin{array}{l}\text { Pele }(53 \% n=15) \\
\text { Boca }(67 \% n=15) \\
\text { Fígado }(54 \% n=13)\end{array}$ & $\begin{array}{l}\text { Náuseas, vômitos, diarreia, dor } \\
\text { abdominal, neutropenia }\end{array}$ & $85 \%$ em 2 anos \\
\hline $\begin{array}{l}\text { Corticoesteroides } \\
\text { em dose alta }\end{array}$ & $\begin{array}{l}46 \% \text { resposta } \\
\text { maior }(n=56)\end{array}$ & & $\begin{array}{l}\text { Infecção, intolerância a glicose, } \\
\text { efeitos psicológicos incluindo } \\
\text { psicose, insônia }\end{array}$ & $88 \%$ em 1 ano \\
\hline $\begin{array}{l}\text { Fotoférese } \\
\text { extracorpórea }\end{array}$ & $\begin{array}{l}61 \% \text { taxa de resposta } \\
(n=71)\end{array}$ & $\begin{array}{l}\text { Pele }(40 \% n=48) \\
\text { Pele esclerótica }(67 \% n=21) \\
\text { Olhos }(67 \% n=4) \\
\text { Boca }(77 \% n=7) \\
\text { Pulmão }(54 \% n=6)\end{array}$ & $\begin{array}{l}\text { Anemia e necessidade potencial } \\
\text { de acesso venoso central }\end{array}$ & $53 \%$ em 1 ano \\
\hline $\begin{array}{l}\text { Sirolimus } \\
\text { (rapamicina) }\end{array}$ & $\begin{array}{l}63-94 \% \text { resposta } \\
\text { clinica }(n=16-35)\end{array}$ & $\begin{array}{l}\text { Pele }(65 \% n=29) \\
\text { Boca }(75 \% n=8) \\
\text { Fígado }(33 \% n=6) \\
\text { Olhos }(64 \% n=11) \\
\text { TGI }(67 \% n=6)\end{array}$ & $\begin{array}{l}\text { Hipertrigliceridemia } \\
\text { insuficiência renal, citopenias, } \\
\text { infeç̧ão }\end{array}$ & $\begin{array}{l}41 \% \text { em } 2 \text { anos } \\
89 \% \text { em } 3 \text { anos }\end{array}$ \\
\hline Pentostatina & $\begin{array}{l}53 \% \text { resposta maior } \\
\text { e } 2 \% \text { resposta } \\
\text { menor }(n=58)\end{array}$ & & $\begin{array}{l}\text { Insuficiência renal, náuseas, } \\
\text { vômitos, Infecção, erupções } \\
\text { cutâneas e cefaléia }\end{array}$ & $78 \%$ em 1 ano \\
\hline Tacrolimus & $\begin{array}{l}35 \% \text { taxa de resposta } \\
(n=39)\end{array}$ & & $\begin{array}{l}\text { Insuficiência renal, } \\
\text { microangiopatia trombótica, } \\
\text { neurotoxicidade e hipertensão }\end{array}$ & Não reportada \\
\hline \multicolumn{5}{|c|}{ Agentes menos comuns } \\
\hline Rituximab & $\begin{array}{l}65-70 \% \text { taxa de } \\
\text { resposta }(n=21-38)\end{array}$ & $\begin{array}{l}\text { Pele }(63 \% n=28) \\
\text { Boca }(48 \% \mathrm{n}=21) \\
\text { Olhos }(43 \% \mathrm{n}=14) \\
\text { Fígado }(25 \% \mathrm{n}=12) \\
\text { Pulmão }(38 \% \mathrm{n}=8)\end{array}$ & $\begin{array}{l}\text { Reações alérgicas, infecções, } \\
\text { reativação de hepatite prévia }\end{array}$ & $76 \%$ em 2 anos \\
\hline Talidomida & $\begin{array}{l}20-38 \% \text { taxa de } \\
\text { resposta }(n=23-80)\end{array}$ & $\begin{array}{l}\text { Pele }(46 \% n=30) \\
\text { Boca }(22 \% n=14) \\
\text { Articulações }(78 \% n=14) \\
\text { Pulmão }(0 \% n=6)\end{array}$ & $\begin{array}{l}\text { Neuropatia, sonolência } \\
\text { constipação, neutropenia }\end{array}$ & $41 \%$ em 2 anos \\
\hline
\end{tabular}

Fonte: RC - resposta completa, RP - resposta parcial, TGI - trato gastrointestinal. Adaptado de Stephanie JL, Mary Flowers ED 
- Talidomida - agente com propriedades imunomodulatórias classicamente utilizada como terapia pós-transplante, porém aparentemente sem papel no período imediato. ${ }^{50}$ Browne e cols ${ }^{51}$ estudaram seu uso em 37 pacientes e observaram 38\% de resposta global (78\% nas articulações e $46 \%$ na pele) e sobrevida de $41 \%$ em dois anos. Estudo prévio $^{52}$ com amostra maior $(n=80)$ reportou $20 \%$ de resposta com alta taxa (36\%) de efeitos adversos e suspensão da droga (Cla).

- Beclometasona oral - fórmulas de liberação imediata e entérica de dipropionato de beclometasona, avaliada em pacientes com DECH-c gastrointestinal na dose de $8 \mathrm{mg} / \mathrm{dia}$ em cursos de 28 dias, associada a $1 \mathrm{mg} / \mathrm{kg} /$ dia de prednisona com desmame após dez dias. Um ensaio randomizado placebo-controlado ${ }^{53} \mathrm{com} 129$ pacientes com doença aguda clássica ou tardia mostrou redução no risco de mortalidade de $66 \%$ no D 200 e de $46 \%$ após um ano de randomização. Iyer e $\operatorname{cols}^{54}$ reportaram resposta de $60 \%$ em 13 pacientes avaliáveis com DECH-c gastrointestinal, necessitando em média três ciclos para resposta (AIa).

- Metotrexato - antimetabólito que, em baixas doses, tem propriedades imunomodulatória e anti-inflamatória. Giaccone e $\operatorname{cols}^{55}$ reportaram 71\% (10/14) de controle de DECHc refratária, com redução de prednisona para dose $<1 \mathrm{mg} / \mathrm{kg} /$ dias alternados, com esquema de $7,5 \mathrm{mg} / \mathrm{m}^{2} / \mathrm{semana}$ de MTX em pacientes com DECH-c refratária, de longa duração e com cinco sítios acometidos em média. Sobrevida de $92,8 \%$, mediana de seguimento 25 semanas, nenhuma toxicidade graus III/IV. Uma série mais recente ${ }^{56}$ de 27 crianças com DECH refratária (17 com forma crônica), tratadas com doses de MTX de $3-10 \mathrm{mg} / \mathrm{m}^{2} / \mathrm{semana}$, mostrou $58,8 \%$ de resposta global para DECH-c com suspensão da prednisona em 7/17 e redução (dose $<0,4 \mathrm{mg} / \mathrm{kg}$ ) em 9/17 pacientes (CIIa).

- Altas doses de metilprednisolona - pulsos com doses de $10 \mathrm{mg} / \mathrm{kg} /$ dia por quatro dias têm papel linfolítico. Akpek e cols $^{57}$ avaliaram 56 pacientes com doença grave refratária, tratados com este esquema e desmame com prednisona subsequente. A taxa de resposta maior foi de $48 \%$, sem efeitos adversos importantes (CIIa).

- Hidroxicloroquina (HCQ) - droga antimalárica 4-amino-quinolina, usada em tratamento de doenças autoimunes, que interfere na apresentação de antígenos e reduz a produção de citocinas pró-inflamatórias como IL-1, IL-6 e TNF- $\alpha$. Gilman e cols, ${ }^{58} \mathrm{em}$ ensaio fase II com HCQ oral $800 \mathrm{mg} /$ dia, reportaram 53\% de resposta global em 32 pacientes com DECH-c resistente ou córtico-dependente. Todos os respondedores toleraram redução $>50 \%$ na dose de prednisona, sendo que os sítios com maior taxa de resposta foram fígado, pele e mucosa oral (CIIa).

Outras opções estão sendo testadas em estudos fase II e I/II incluindo daclizumab,,${ }^{59}$ etarnecept ${ }^{60}$ imatinibe, ${ }^{61}$ alefacept ${ }^{62}$ alemtuzumab ${ }^{63}$ pulso de ciclofosfamida, ${ }^{64}$ clofazimina ${ }^{65}$ etretinato, ${ }^{66}$ pravastatina, ${ }^{67}$ budesonida oral ${ }^{68}$ e infusão de células-tronco mesenquimais ${ }^{69}$
Pacientes com DECH-c, especialmente aqueles em uso de imunossupressores sistêmicos, devem receber antibiótico profilático contra bactérias encapsuladas (BIIa); vacinas anti-hemófilos influenza tipo b (Hib conjugada), antipneumocóccica (BIIb) e influenza injetável (BIII); SMX/TMP para prevenir Pneumocystis (AIIa); IGIV quando nível sérico de $\operatorname{IgG}<400 \mathrm{mg} / \mathrm{dl}$ e infecções sinopulmonares de repetição (CIII); profilaxia antifungo filamentoso em pacientes com infecção fúngica prévia e/ou alto grau de imunossupressão (AIa). Os pacientes com reativação prévia de citomegalovírus (CMV), linfopenia e/ou DECH-c em atividade têm maior risco de reativação tardia. Alguns centros monitoram o CMV após o D 100 por antigenemia pp65 ou PCR cada uma a quatro semanas, instituindo tratamento preemptivo quando necessário (CIIa). ${ }^{11}$

Em face da multiplicidade de manifestações, do grau de acometimento, da combinação de sítios envolvidos e da disponibilidade de agentes terapêuticos em cada centro, o tratamento de resgate de DECH-c dependente ou refratária a corticosteroide costuma ser individualizado, o que dificulta a realização de estudos prospectivos controlados, com tamanho amostral suficiente para definições de resposta, ${ }^{70} \mathrm{e} o$ estabelecimento de diretrizes. Sugerimos que estes casos sejam protocolados em estudos multicêntricos e recebam abordagem multidisciplinar. A terapia de resgate ideal ainda não está definida. ${ }^{71}$ Nos centros com disponibilidade, o uso de FEC deve ser considerado o mais precoce possível na terapia secundária de DECH-c cutânea ou cutâneo-mucosa. ${ }^{72}$ As alterações músculo-esqueléticas parecem responder bem ao uso de rituximab, e o papel do metotrexato nestes casos, como alternativa de menor custo, precisa ser mais bem definido. Na DECH-c com envolvimento visceral, o tratamento deve ser dirigido ao órgão mais afetado, por exemplo, MMF e/ou tacrolimus para fígado, anti-TNF- $\alpha$ ou sirolimus para intestino e altas doses de metilprednisolona e rituximab para pulmão.

\section{Terapia adjuvante dermatológica}

A terapia de suporte dermatológico inclui agentes tópicos com ação anti-inflamatória e imunossupressora, e medidas diretas, como educacionais, psicossociais e preventivas, que controlem os sintomas ou complicações consequentes da DECH e terapias utilizadas para tratá-la. Estas recomendações foram organizadas de acordo com um sistema baseado em evidências que refletem a força de recomendação e a qualidade de evidências que as suportam baseado nos critérios do $\mathrm{NIH}^{11}$ (Tabela 9). O foco da terapia de suporte está na prevenção, manuseio de alterações dermatológicas e sintomas como prurido, lesões máculopapulosas, dor, despigmentação, redução da mobilidade das articulações e tratamento tópico de erosões, ulcerações e superinfecção. Na ausência de fatores de mau prognóstico, como trombocitopenia $(<100000 / \mu \mathrm{L})$, tratamento com 
Tabela 9. Sistema de graduação baseado em evidências para suporte da $\mathrm{DECH}-\mathrm{c}^{10}$

\begin{tabular}{ll}
\hline Categoria & Definição \\
\hline Força da Recomendação: & Deveria sempre ser oferecida \\
A & Deveria geralmente ser oferecida \\
B & Evidência de eficácia é insuficiente para dar suporte a recomendação a favor ou contra, ou evidência de \\
C & Moderácia talvez não compense os efeitos adversos ou os custos da abordagem. Opcional. \\
D & Não deveria geralmente ser oferecido ou por efeitos adversos que recomendem contra a utilização. \\
E & Grandes evidências de falta de eficácia ou por efeitos adversos que recomendem contra a utilização. \\
Qualidade da evidência que suporte a recomendação: \\
I & Evado deveria nunca ser oferecido \\
II & Evidência de $\geq$ I estudo clínico bem desenhado sem randomização de um cohort ou estudos de análise \\
& caso controle (preferência para estudos que contenham mais de 1 centro) ou de múltiplos casos ou \\
III & resultados dramáticos de estudos não controlados \\
Avaliadores de categorias I e II: & Evidências de opiniões de especialistas baseadas em estudos clínicos descritivos \\
a & Evidências derivadas indiretamente de estudo(s) de doenças semelhantes \\
\hline
\end{tabular}

corticoide no momento do diagnóstico, DECH-c cutânea com envolvimento de $>50 \%$ de superfície corporal total e pontuação global moderada ou grave, os agentes tópicos podem ser utilizados como tratamento primário para $\mathrm{DECH}-\mathrm{c}$ cutânea (Tabela 10). ${ }^{11}$

Medidas de prevenção para o desenvolvimento $e$ exacerbação da DECH

A radiação ultravioleta (UV) pode causar exacerbação da DECH cutânea. ${ }^{73}$ Fotoproteção inclui roupas protetoras, evitar a exposição solar, uso de fotoprotetores químicos e físicos que protegem tanto para radiação UVAe UVB ( dióxido de titâneo, Mexoryl SX ou avobenzona).

\section{Terapias e cuidados locais para manter intacta} a barreira cutânea

Na pele intacta, a lubrificação com emolientes à base de cremes e pomadas diminui o prurido. Pomadas e cremes são emolientes melhores do que loções que promovem sensação de ardência na pele eritematosa.

Lesões cutâneas não escleróticas sem erosões ou ulcerações (liquen plano like ou lesões eritemato-papulosas) podem responder bem a esteroides tópicos e emolientes. $\mathrm{O}$ uso prolongado de corticoides tópicos pode levar a atrofia cutânea localizada e desenvolvimento de estrias.

Esteroides tópicos de alta potência, como propionato de clobetasol e fluocinolona, para áreas pequenas e por curto tempo, assim como os de baixa e média potência para áreas mais extensas, como triancinolona, desonida e hidrocortisona, podem ser utilizados como terapia adjuvante. Anti-histamínicos orais sem metabolização hepática, como a fexo- fenadina e a epinastina, são utilizados para reduzir o prurido. Para DECH-c refratária a corticoterapia sistêmica, a fototerapia com UVB de banda estreita (narrow band)/PUVA tem sido empregada com bons resultados. ${ }^{74-77}$

Recentemente, o emprego de inibidores da calcineurina $^{11,78,79}$ (pimecrolimo e tacrolimo) tem sido relatado com frequência maior, com o objetivo de melhorar o eritema e prurido, com redução do uso prolongado de esteroides tópicos.

Medicações tópicas clareadoras à base de hidroquinona, sozinha ou em associação com tretinoína tópica e esteroides, podem ser utilizadas para tratar hiperpigmentação pós-inflamatória residual.

Terapia tópica e cuidados para pele não intacta

Para lesões cutâneas ulceradas/erosões, culturas microbiológicas podem ser realizadas para pesquisa de infecções bacterianas, virais, fúngicas e micobacterianas. $\mathrm{O}$ diagnóstico diferencial das lesões cutâneas não infecciosas inclui vasculite, malignidade recorrente, DECH, hiper-sensibilidade, reações a drogas, eczemas e câncer cutâneo primário. $\mathrm{Na}$ área desnuda, antimicrobianos tópicos (mupirocina), produtos contendo prata (sulfadiazina de prata a 1\%), curativos à base de filmes protetores para estimular cicatrização, desbridamento das feridas, podem ser úteis.

Feridas recalcitrantes devem ser abordadas em conjunto com o cirurgião plástico e/ou dermatologista, e aquelas com cicatrização lenta podem ser tratadas com produtos à base de ácido hialurônico, colágeno, fibroblastos e queratinócitos. Terapia com oxigênio hiperbárico tem sido utilizada em feridas com pouca oxigenação. ${ }^{80}$ 
Tabela 10. Terapia de suporte dermatológico para DECH-c cutânea ${ }^{10}$

\begin{tabular}{|c|c|}
\hline Medidas de Prevenção & Graduação \\
\hline $\begin{array}{l}\text { Fotoproteção: bloqueadores anti-UVA e anti-UVB } \\
\text { ( } \geq \text { FPS30) }\end{array}$ & Alll \\
\hline $\begin{array}{l}\text { Evitar exposição solar (especialmente entre } \\
\text { 10:00 e 16:00h) }\end{array}$ & Alll \\
\hline Proteção com roupas & Alll \\
\hline \multicolumn{2}{|l|}{$\begin{array}{l}\text { Tratamento } \\
\text { *Pele intacta }\end{array}$} \\
\hline $\begin{array}{l}\text { Tratamento sintomático com agentes emolientes e } \\
\text { antipruriginosos }\end{array}$ & Alll \\
\hline Corticosteroides tópicos & Cllb \\
\hline $\begin{array}{l}\text { Fototerapia (PUVA, UVA1, UVB, UVB-banda } \\
\text { estreita) }\end{array}$ & Clla \\
\hline $\begin{array}{l}\text { Inibidores tópicos da calcineurina (pimecrolimo } \\
\text { e tacrolimo) }\end{array}$ & Clla \\
\hline \multicolumn{2}{|l|}{ *Manifestações de esclerose acometendo articulação } \\
\hline Massagem muscular profunda/fáscia & CIII \\
\hline Avaliação da força muscular a cada consulta & BIII \\
\hline Orientação quanto à terapia física e ocupacional & Alll \\
\hline Exercícios de estiramento & Alll \\
\hline Exercícios isocinéticos, isométricos, isotônicos & All \\
\hline Liberação cirúrgica & DIII \\
\hline \multicolumn{2}{|l|}{${ }^{\star}$ Erosões e ulcerações } \\
\hline Antimicrobianos oral e tópico & BIII \\
\hline Desbridamento e curativos oclusivos nas feridas & CIII \\
\hline Controle de edema & BIII \\
\hline \multicolumn{2}{|l|}{ Considerações pediátricas } \\
\hline \multicolumn{2}{|c|}{$\begin{array}{l}\text { Efeitos adversos sistêmicos dos esteroides tópicos podem } \\
\text { ocorrer com frequência em crianças devido à grande superfície } \\
\text { a ser tratada }\end{array}$} \\
\hline \multicolumn{2}{|c|}{$\begin{array}{l}\text { Embora os esteroides tópicos de baixa potência ( } 1 \% \text { a } 2,5 \% \\
\text { hidrocortisona) sejam seguros, esteroides de média e alta } \\
\text { potência podem ser usados em áreas limitadas por intervalo } \\
\text { curto de tempo (<3-4 semanas) }\end{array}$} \\
\hline \multicolumn{2}{|l|}{ Esteroides tópicos sob oclusão não são recomendados } \\
\hline $\begin{array}{l}\text { O uso de esteroides potentes em crianças }<1 \text { ano } \\
\text { recomendado }\end{array}$ & não é \\
\hline
\end{tabular}

Terapia compressiva pode ser indicada para facilitar a drenagem em feridas com edema ao redor.

Terapia adjuvante para DECH-c com envolvimento oral

$\mathrm{O}$ envolvimento da cavidade oral na DECH-c é frequente, podendo estar presente em cerca de $70 \%$ a $83 \%$ naqueles pacientes submetidos ao TCTH alogênico. ${ }^{81}$

As manifestações clínicas orais incluem inflamação oral (eritema) e atrofia do epitélio da mucosa, lesões liquenoides (liquen-like) com alterações hiperceratóticas, pseudomembranosas ou atróficas, podendo atingir toda a mucosa oral, sem preferência no local de acometimento. A DECH-c também pode afetar glândulas salivares maiores e menores, em proporções não necessariamente iguais à mucosa. Quando acomete glândulas salivares, clinicamente ocorre o espessa- mento da saliva, levando à hiposalivação (xerostomia como sintoma objetivo relatado pelo paciente) e formação de mucoceles (cisto de retenção de muco, por alterações ductais). Histologicamente pode ser observada a destruição de lóbulos salivares por infiltração linfocitária, perdas ductais levando à total destruição das unidades secretórias, muitas vezes de forma permanente, levando à xerostomia. Essas alterações levam a modificações da microflora oral, com consequente aumento do índice de doenças infecciosas orais, como a cárie dentária e doença periodontal.

$\mathrm{O}$ tratamento da DECH-c oral pode incluir agentes imunossupressores sistêmicos ou não. Em casos de acometimento leve a moderado, o tratamento tópico pode constituir-se na terapia de escolha, ou mesmo ser utilizado como coadjuvante, em casos mais graves, associado ao tratamento sistêmico.

A literatura oferece diversas opções para o tratamento tópico, ${ }^{11,81-94}$ que estão listadas nas Tabelas 9 e 11.

\section{Terapia adjuvante oftalmológica}

O espectro clínico da DECH-c ocular inclui inflamação conjuntival aguda, conjunvite cicatricial e pseudomembranosa e síndrome de ceratoconjuntivite Sicca (SCS). A SCS frequentemente acompanha a atividade em outros órgãos da DECH-c, porém pode ser sua única manifestação. ${ }^{95} \mathrm{O}$ diagnóstico de SCS é feito pela presença de sintomas próprios, produção de lágrima em média de $5 \mathrm{~mm}$ (teste de Schirmer) e sinais clínicos de ceratite. Apesar da clínica sugestiva, o exame pela lâmpada de fenda pelo oftalmologista é importante para o diagnóstico de SCS. Sintomas incluem queimação, irritação, dor, sensação de corpo estranho, visão borrada, fotofobia e, paradoxalmente, excesso de lágrimas. ${ }^{96}$ Outras causas de olho seco incluem medicações com efeitos adversos anticolinérgicos (anti-hipertensivos, antidepressivos, psicotrópicos, anti-histamínicos, descongestionantes) e tratamentos prévios (ex. irradiação corporal total, quimioterapia, história de TCTH autólogo. Embora as terapias imunossupressoras sistêmicas para DECH-c não levem à melhora dos escores de Schirmer (especialmente se a disfunção da glândula lacrimal é de longo prazo), elas podem melhorar os sintomas gerais da $\mathrm{DECH}$ ocular.

A terapia de suporte oftalmológico inclui aumento da hidratação ocular (lubrificação e diminuição da evaporação e drenagem da lágrima da superfície ocular) e diminuir a inflamação da superfície ocular (Tabela 9 e Tabela 12). ${ }^{81}$

\section{Lubrificação}

Recomenda-se o uso de lágrimas artificiais livres de preservativos, minimizando a ceratopatia pontuada superficial (pontos secos na córnea), diminuindo os sintomas oculares e melhorando a qualidade da visão. Para pacientes que necessitam de aplicação de lágrimas artificiais mais do que de hora em hora, recomenda-se dissolver vagarosamente 
Tabela 11. Terapia adjuvante para DECH-c com envolvimento oral

\begin{tabular}{|c|c|c|c|}
\hline $\begin{array}{l}\text { Tratamento } \\
\text { Categoria }\end{array}$ & Tratamento & Instrução de uso & $\begin{array}{l}\text { Escore } \\
\text { evidência }\end{array}$ \\
\hline \multicolumn{4}{|l|}{ Corticosteroides } \\
\hline \multirow[t]{4}{*}{$\begin{array}{l}\text { Corticoides } \\
\text { Bochechos }\end{array}$} & Dexametasona & $\begin{array}{l}0.1-0.4 \mathrm{mg} / \mathrm{mL} \text { concentração; bochechar } 5-10 \mathrm{~mL} \text { e } \\
\text { segurar na boca por } 3-5 \mathrm{~min} \text {. Cuspir, Repetir } 3-6 \times \text { /dia }\end{array}$ & Alla \\
\hline & Budesonida & $\begin{array}{l}0,3-0.6 \mathrm{mg} / \mathrm{mL} \text { de concentração. Bochechar } 10 \mathrm{~mL} \text { e } \\
\text { segurar por } 15 \mathrm{~min} \text { na boca. Cuspir e repetir } 2-4 \mathrm{X} / \mathrm{dia}\end{array}$ & Alla \\
\hline & Betametasona & $\begin{array}{l}0.5 \mathrm{mg} \text { tablete dissolvido em } 10 \mathrm{~mL} \text { de água, segurar na boca } \\
\text { por } 3 \text { minutos, cuspir e repetir } 3-4 \mathrm{x} / \mathrm{dia}\end{array}$ & Alla \\
\hline & Prednisona & $3 \mathrm{mg} / \mathrm{mL}$ bochechar $5 \mathrm{~mL}$ por $4-6 \mathrm{~min}$, cuspir e repetir 3-6x/dia & Alla \\
\hline $\begin{array}{l}\text { Sprays e } \\
\text { Inalatórios }\end{array}$ & $\begin{array}{l}\text { Beclometasona } \\
\text { Betametasona } \\
\text { Fluticasona }\end{array}$ & $\begin{array}{l}\text { 1-2 Puffs na boca. Repetir } 2-4 \times / \text { dia. Segurar na boca, não engolir } b \\
\text { 1-2 puffs na boca. Repetir } 2-4 \times / d^{b} a^{b} \\
1-2 \text { puffs na boca. Repetir } 2-4 \times / d^{b} a^{b}\end{array}$ & Alla \\
\hline $\begin{array}{l}\text { Géis, cremes e } \\
\text { pomadas }^{c}\end{array}$ & $\begin{array}{l}0.05 \% \text { clobetasol creme, pomada, } \\
\text { solução gel } \\
0,05 \% \text { fluocinonida creme, pomada e } \\
\text { gel } \\
0.1-0.5 \% \text { triancinolona creme } \\
0,05 \%-0,1 \% \text { betametasona creme, } \\
\text { pomada }\end{array}$ & $\begin{array}{l}\text { Aplicar na lesão 2x/dia } \\
\text { Aplicar na lesão } 2 x / \text { dia } \\
\text { Aplicar na lesão } 2 x / \text { dia } \\
\text { Aplicar na lesão } 2 x / \text { dia }\end{array}$ & Alla \\
\hline Intralesional & Triancinolona 40mg & Injetar 0,3-0,4ml por $\mathrm{cm}^{2}$ lesão & BIII \\
\hline Analgésicos & $\begin{array}{l}\text { Lidocaína } 2 \% \text {, Kaopectate, benadryl, } \\
\text { 1:1:1 }\end{array}$ & Aplicar em forma de bochechos $4-6$ vezes ao dia & Alll \\
\hline $\begin{array}{l}\text { Agentes } \\
\text { colinérgicos } \\
\text { (terapia sialogoga) }\end{array}$ & $\begin{array}{l}\text { Cevimeline } \\
\text { Pilocarpina }\end{array}$ & $\begin{array}{l}\text { Tomar } 1 \mathrm{cp}(30 \mathrm{mg}) 3 \times \text { dia } \\
\text { Tomar } 1 \mathrm{cp}(5 \mathrm{mg}) 4 \times \mathrm{dia}\end{array}$ & $\begin{array}{l}\mathrm{Blb} \\
\mathrm{Blb} / \mathrm{lla}\end{array}$ \\
\hline \multicolumn{4}{|l|}{$\begin{array}{l}\text { Imunossupressores } \\
\text { não esteroides }\end{array}$} \\
\hline \multirow[t]{2}{*}{ rinses } & Ciclosporina $^{\mathrm{d}}$ & $\begin{array}{l}\text { Rinse: } 100 \mathrm{mg} / \mathrm{mL} 5 \mathrm{~mL} \text { bochechar e segurar por alguns minutos, } \\
\text { cuspir e repetir } 3 \times / \text { dia }\end{array}$ & Clla/lb \\
\hline & Azatioprina/ 6-mercaptopirina & $\begin{array}{l}1.5 \% \text { gel aplicado na lesão, } 2-4 \times / \text { dia } \\
5-10 \mathrm{mg} / \mathrm{mL}, 5-10 \mathrm{~mL} \text { bochechar e segurar na boca por } 3-5 \mathrm{~min} \text {, } \\
\text { cuspir e repetir } 2-6 x / \text { dia }\end{array}$ & CIII \\
\hline \multirow[t]{3}{*}{ Géis/ outros } & Ciclosporina & $0,5 \mathrm{mg} / \mathrm{dL}$ em material ora-base & $\mathrm{Clla} / \mathrm{lb}$ \\
\hline & Azatioprina & $\begin{array}{l}5 \mathrm{mg} / \mathrm{mL} \text { em } 3 \% \text { base gel de metilcelulose, } 1-2 \mathrm{~mL} \text { aplicado na } \\
\text { lesão, } 2-4 x / \text { dia }\end{array}$ & CIII \\
\hline & Tacrolimus $(0,1 \%)$ & $\begin{array}{l}\text { Aplicar } 0,5 \mathrm{~cm} \text { na gaze, segurar sobre a lesão por } 15-20 \mathrm{~min} 2 \mathrm{x} / \mathrm{d} \text {. } \\
\text { Monitorar níveis plasmáticos }\end{array}$ & Blla \\
\hline \multirow[t]{3}{*}{ Fototerapia oral } & PUVA & 0,4-0,6mg/Kg de psoraleno seguido de radiação UVA & Clla \\
\hline & UVB banda larga/ & Sem necessidade ingestão psoraleno & \\
\hline & $\begin{array}{l}\text { UVB banda estreita } 311 \mathrm{~nm} \\
\text { (narrow band) }\end{array}$ & Tratamento deve ser realizado 3 vezes na semana & Clla \\
\hline
\end{tabular}

Adaptado de Schubert \& Correa. Oral Graft Versus Host Disease, Dent Clin North Am. 2008 Jan;52(1):79-109, 2008. PUVA = psoraleno associado com ultravioleta A a = provável necessidade de profilaxia antifúngica (Candida $s p$ ) principalmente quando no uso de inalatórios. $\mathrm{b}=$ considerar lavar a cavidade oral após 15-20 min na tentativa de redução do risco de infecção fúngica Candida $s p)$. $\mathrm{c}=$ pomadas e géis podem ser aplicadas no local com auxílio de gaze e permanecer por 10-15 minutos. $d=$ Ciclosporina, por ser cara, o volume a ser utilizado pode ser diminuído para $1-3 \mathrm{~mL}$ para cada bochecho

cinco gotas de hidroxipropilmetilcelulose. ${ }^{97}$ Medicações orais podem ser utilizadas para aumentar a lubrificação por estímulo da lágrima aquosa através de agonistas muscarínicos seletivos como pilocarpina e cevimeline. ${ }^{98}$

Controle da evaporação

Para diminuir a evaporação, os pacientes devem ser orientados a utilizar compressas mornas, evitar baixa umidade e uso de protetores oculares. Para casos refratários, cirurgia para reduzir as áreas expostas (tarsorafia) pode ser necessária. ${ }^{99}$

Controle da drenagem

A redução da drenagem da superfície dos olhos, oclusão temporária ou permanente do ducto lacrimal pode 
Tabela 12. Terapia de Suporte para DECH-c Oftalmológica 80

\begin{tabular}{|c|c|c|}
\hline Terapia & Indicação & Escore \\
\hline \multirow[t]{2}{*}{ Tópico } & $\begin{array}{l}\text { Médio } \\
\text { Lágrimas artificiais livres preservativos } \\
\text { Pomada viscosa à noite, lágrima viscosa durante o dia }\end{array}$ & $\begin{array}{l}\text { Alb } \\
\text { Blb }\end{array}$ \\
\hline & $\begin{array}{l}\text { Moderado/Grave } \\
\text { Colírios a base de ciclosporina } \\
\text { Colírios a base de corticoides } \\
\text { Lacriserts para pacientes que usam lágrimas artificiais mais frequente do que hora/hora }\end{array}$ & $\begin{array}{l}\text { Clb } \\
\text { Bllla } \\
\text { Clb }\end{array}$ \\
\hline Oral & $\begin{array}{l}\text { Moderado/Grave } \\
\text { Cevimeline } \\
\text { Pilocarpina } \\
\text { Doxiciclina }\end{array}$ & $\begin{array}{l}\mathrm{Clb} \\
\mathrm{Clb} \\
\mathrm{ClII}\end{array}$ \\
\hline Cirurgia & $\begin{array}{l}\text { Moderada/grave } \\
\text { Oclusão pontual (oclusão permanente ou temporária, usando cola silicone ou } \\
\text { cauterização térmica). } \\
\text { Debridamento superficial da ceratite filamentosa } \\
\text { Tarsorafia parcial }\end{array}$ & $\begin{array}{l}\text { Blb } \\
\text { CIII } \\
\text { Cllb }\end{array}$ \\
\hline Proteção ocular & $\begin{array}{l}\text { Moderada/grave } \\
\text { Protetores oclusivos para os olhos } \\
\text { Cuidados com as pálpebras/ compressas mornas/ umidificação do meio ambiente } \\
\text { Lentes de contato terapêuticas (usado com extremo cuidado) }\end{array}$ & $\begin{array}{l}\text { BIII } \\
\text { CIII }\end{array}$ \\
\hline $\begin{array}{l}\text { Tratamento não } \\
\text { amplamente disponível }\end{array}$ & $\begin{array}{l}\text { Moderado/grave } \\
\text { Soro autólogo }\end{array}$ & $\mathrm{Clb}$ \\
\hline
\end{tabular}

Considerações pediátricas: Embora a Sicca ocular seja incomum em crianças com DECH-c, a produção da lágrima é diminuída e acompanhamento da ceratoconjuntivite Sicca é necessário. Sicca ocular geralmente responde a terapia de suporte em conjunto com imunossupressão sistêmica. A experiência é limitada e a dose não é estabelecida para muitas medicações orais e tópicas para DECH ocular

fornecer benefícios adicionais para pacientes com síndrome Sicca ocular grave $\left(<5\right.$ mm lágrima) ${ }^{100}$ A oclusão pontuada permanente (por cauterização térmica) poderá ser necessária, pois os plugs de silicone usados para oclusão temporária falham com frequência. Cauterização térmica repetida pode ser necessária se houver reabertura dos pontos.

Diminuição da inflamação da superfície ocular

$\mathrm{O}$ uso de corticoide tópico deve ser reservado para controlar a exacerbação da DECH-c ocular quando a imunossupressão sistêmica está sendo reduzida. ${ }^{101}$ Pulsos de corticoterapia tópica devem ser cuidadosamente supervisionados por um oftalmologista, porque as complicações incluem aumento da pressão intraocular, formação de cataratas, ceratite infecciosa silenciosa. Ciclosporina tópica pode ser prescrita para controlar respostas imunes na superfície ocular. ${ }^{102,103}$ Seu benefício na DECH-c ocular ainda não está bem esclarecido, mas parece aumentar os escores de Schirmer e diminuir a apoptose em pacientes com outras condições que levam a olho seco.

Em alguns relatos, a doxiciclina foi utilizada em pacientes com olho seco e demonstrou eficácia na diminuição da atividade gelatinosa do epitélio ocular, com melhora da regularidade da superfície córnea e melhora da função de barreira córnea. ${ }^{104}$

Em nível celular, a doxiciclina preserva a área celular epitelial apical, resultando em uma redução do número de descamação das células epiteliais da superfície da córnea.
A inflamação da superfície ocular pode ser reduzida com uma solução de $20 \%$ de soro autólogo e salina estéril aplicada 10 vezes ao dia. ${ }^{105-107}$ Soro autólogo tem sido utilizado porque contém vitaminas, diversos fatores de crescimento e fibronectina, que são importantes para a integridade da córnea e conjuntiva. ${ }^{108,109}$

Soro autólogo é indicado para o tratamento da xeroftalmia grave associada à DECH-c ocular para renovar os componentes do filme lacrimal e da superfície ocular. ${ }^{110,111}$

\section{Terapia adjuvante ginecológica}

O diagnóstico da DECH-c vulvovaginal é estabelecido por achados físicos e sintomas, que se apresentam como anormalidades da mucosa ou alterações escleróticas. ${ }^{12,113}$ Sintomas podem incluir disúria, secura, sensibilidade ao toque e dispareunia. A DECH-c vulvovaginal leve pode ser assintomática e detectada somente ao exame ginecológico. Achados físicos incluem manchas vermelhas (mucosite), leucoceratose retiforme (lesões tipo liquen plano-like), sensibilidade vestibular, e, menos frequentemente, escoriações e úlceras.

A esclerose da vulvovaginal pode levar a mudanças arquiteturais tal como fimose do clitoris, estreitamento do introito e encurtamento do canal vaginal. A confirmação histológica é recomendada na ausência de manifestações diagnósticas de DECH-c em outros órgãos. Deficiência de estrogênio e infecções (papiloma vírus humano, herpes 
Tabela 13. Terapia de Suporte para DECH-c vulvovaginal

\begin{tabular}{lc}
\hline Tipo de intervenção & Escore \\
\hline Desconforto vulvar & BIII \\
Evitar irritantes químicos e mecânicos(ex. sabões e produtos para higiene) & BIII \\
Lavar a área genital com água morna, permitir a circulação de ar e limpar da frente para trás & BIII \\
Espalhar emolientes na vulva & BIII \\
Lubrificantes a base de água & BIII \\
Sintomas vulvovaginais e nível de estrogênio baixo & BIlb \\
Estrogênio tópico com /sem dilatador(dilatador necessário somente para sintomas vaginais) & BII \\
Terapia tópica para DECH-c vulvovaginal & BIlb \\
Corticoides de alta potência & BIII \\
Propionato de Clobetasol gel 0,05\%(vagina) & \\
Pomada de tacrolimo 0,1\% (vulva) & pomada (vulva) \\
Terapia cirúrgica & Lise cirúrgica com ou sem reconstrução vaginal seguida de 6 meses de terapia dilatadora \\
Pode ser necessária para tratamento de sinéquia extensa e completa obliteração do canal vaginal & \\
\hline
\end{tabular}

Considerações pediátricas: $\mathrm{DECH}-\mathrm{c}$ vulvovaginal precisa ser diagnosticada logo no início do desenvolvimento físico (desde telarca até puberdade). $\mathrm{DECH}-\mathrm{c}$ vulvovaginal é infrequente em meninas pré-puberais

vírus simples, candidíase, bactérias ou outros patógenos ginecológicos reconhecidos) devem ser afastados no momento do diagnóstico inicial e periodicamente durante o tratamento da DECH-c vulvovaginal. (Tabela 13).

\begin{abstract}
The lack of widely-used standardized diagnostic criteria may impair both the true evaluation of chronic graft-versus-host disease and the correlation of its severity with transplant-related mortality. At the I Consensus of the Brazilian Society of Bone Marrow Transplantation-SBTMO that took place in June 2009, the Group of GVHD Studies Brazil-Seattle (GEDECH), presented the guidelines for diagnosis, classification, prophylaxis and treatment of chronic GVHD as proposed by the National Institutes of Health and based on the reality in Brazilian Centers. These proposals, including standardization of features used in diagnosis and tools to score involved organs and to assess the overall severity, should be used in clinical studies of chronic graft-versus-host disease. These criteria are useful to better analyze the incidence of this disease, in addition to evaluate the extension of the involvement of organs or the site affected and its influence on late transplantation mortality. Prophylaxis and treatment proposed for this important complication of hematopoietic stem cell transplantations were discussed and graded according to the levels of evidence established by the National Institutes of Health. Rev. Bras. Hematol. Hemoter. 2010;32(Supl. 1):22-39.
\end{abstract}

Key words: Bone marrow transplantation; diagnosis; classification.

\section{Referências Bibliográficas}

1. Shulman HM, Sullivan KM, Weiden PL, et al. Chronic graftversus-host syndrome in man. A long-term clínicopathologic study of 20 Seattle patients. Am J Med. 1980;69(2):204-17.

2. Wingard JR, Piantadosi S, Vogelsang GB, et al. Predictors of death from chronic graft-versus-host disease after bone marrow transplantation. Blood. 1989;74(4):1428-35.

3. Sullivan KM, Witherspoon RP, Storb R, et al. Prednisone and azathioprine compared with prednisone and placebo for treatment of chronic graft-v-host disease: prognostic influence of prolonged thrombocytopenia after allogeneic marrow transplantation. Blood. 1988;72(2):546-54.

4. Lee SJ, Klein JP, Barrett AJ, et al. Severity of chronic graft-versushost disease: association with treatment-related mortality and relapse. Blood. 2002;100(2):406-14.

5. Akpek G, Lee SJ, Flowers ME, et al. Performance of a new clinical grading system for chronic graft-versus-host disease: a multicenter study. Blood. 2003;102(3):802-9.

6. Arora M, Burns LJ, Davies SM, et al. Chronic graft-versus-host disease: a prospective cohort study. Biol Blood Marrow Transplant. 2003;9(1):38-45.

7. Stewart BL, Storer B, Storek J, et al. Duration of immunosuppressive treatment for chronic graft-versus-host disease. Blood. 2004; 104(12):3501-6

8. Filipovich AH, Weisdorf D, Pavletic S, et al. National Institutes of Health consensus development project on criteria for clinical trials in chronic graft-versus-host disease: I. Diagnosis and staging working group report. Biol Blood Marrow Transplant. 2005;11(12):945-56.

9. Martin PJ, Weisdorf D, Przepiorka D, Hirschfeld S, Farrell A, Rizzo JD, et al; Design of Clinical Trials Working Group National Institutes of Health Consensus Development Project on Criteria for Clinical Trials in Chronic Graft-versus-Host Disease: VI. Design of Clinical Trials Working Group report. Biol Blood Marrow Transplant. 2006;12(5):491-505.

10. Pavletic SZ, Martin P, Lee SJ, Mitchell S, Jacobsohn D, Cowen EW, et al; Response Criteria Working Group. Measuring therapeutic response in chronic graft-versus-host disease: National Institutes of Health Consensus Development Project on Criteria for Clinical 
Trials in Chronic Graft-versus-Host Disease: IV. Response Criteria Working Group report. Biol Blood Marrow Transplant. 2006; 12(3):252-66.

11. Couriel D, Carpenter PA, Cutler C, Bolaños-Meade J, Treister NS, Gea-Banacloche J, et al. Ancillary therapy and supportive care of chronic graft-versus-host disease:national institutes of health consensus development project on criteria for clinical trials in chronic Graft-versus-host disease: V. Ancillary Therapy and Supportive Care Working Group Report. Biol Blood Marrow Transplant. 2006;12(4):375-96.

12. Shulman HM, Kleiner D, Lee SJ, Morton T, Pavletic SZ, Farmer E, et al. Histopathologic diagnosis of chronic graft-versus-host disease: National Institutes of Health Consensus Development Project on Criteria for Clinical Trials in Chronic Graft-versus-Host D. Disease: II. Pathology Working Group Report. Biol Blood Marrow Transplant. 2006;12(1):31-47.

13. Schultz KR, Miklos DB, Fowler, Cooke K, Shizuru J, Zorn E, et al. Toward biomarkers for chronic graft-versus-host disease: National Institutes of Health consensus development project on criteria for clinical trials in chronic graft-versus-host disease: III. Biomarker Working Group Report. Biol Blood Marrow Transplant. 2006;12 (2):126-37

14. Blume KG, Beutler E, Bross $\mathrm{KJ}$, et al. Bone-marrow ablation and allogeneic marrow transplantation in acute leukemia. N Engl J Med. 1980;302(19):1041-6.

15. Kansu E, Gooley T, Flowers MED, et al. Administration of cyclosporine for 24 months compared with 6 months for prevention of chronic graft-versus-host disease: a prospective randomized clinical trial[brief report]. Blood. 2001;98:3868-70.

16. Chao NJ, Parker PM, Niland JC, et al. Paradoxical effect of thalidomide prophylaxis on chronic graft-vs-host disease. Biol Blood Marrow Transplant. 1996;2(2):86-92.

17. Cutler C, Li S, Ho VT, Koreth J, Alyea E, Soiffer RJ, et al. Extended follow-up of methotrexate-free immunosuppression using sirolimus and tacrolimus in related and unrelated donor peripheral blood stem cell transplantation. Blood. 2007;109(7):3108-14.

18. Bacigalupo A, Lamparelli T, Bruzzi P, et al. Antithymocyte globulin for graft-versus-host disease prophylaxis in transplants from unrelated donors: 2 randomized studies from Gruppo Italiano Trapianti Midollo Osseo (GITMO). Blood. 2001;98(10):2942-7.

19. Deeg HJ, Storer BE, Boeckh M, et al. Reduced incidence of acute and chronic graft-versus-host disease with the addition of thymoglobulin to a targeted busulfan/cyclophosphamide regimen. Biol Blood Marrow Transplant. 2006;12(5):573-84.

20. Bacigalupo A, Lamparelli T, Barisione G, Bruzzi P, Guidi S, Alessandrino PE, et al. Thymoglobulin prevents chronic graftversus-host disease, chronic lung dysfunction, and late transplantrelated mortality: long-term follow-up of a randomized trial in patients undergoing unrelated donor transplantation. Biol Blood Marrow Transplant. 2006;12(5):560-5.

21. Soiffer RJ \& Martin P. T-cell depletion of allogeneic hematopoietic stem cell grafts. In Atkinson K, Champlin R, Ritz J et al (eds.) Clinical bone marrow and blood stem cell transplantation. $3^{\text {rd }}$ ed. Cambridge, UK: Cambridge University Press 2004, pp. 416-425.

22. Kottaridis PD, Milligan DW, Chopra R, et al. In vivo: CAMPATH$1 \mathrm{H}$ prevents graft-versus-host disease following nonmyeloablative stem cell transplantation. Blood. 2000;96(7):2419-25.

23. Arora M. Therapy of chronic graft-versus-host disease. Best Prac \& Res Clin Haematol. 2008;21(2):271-279.

24.Koc S, Leisenring W, Flowers ME, Anasetti C, Deeg HJ, Nash RA, et al. Therapy for chronic graft-versus-host disease: a randomized trial comparing cyclosporine plus prednisone versus prednisone alone. Blood. 2002;100(1):48-51.
25. Lee SJ, Flowers ME. Recognizing and managing chronic graftversus-host disease. Hematology Am Soc Hematol Educ Program. 2008:134-41.

26. Martin PJ, Carpenter PA, Sanders JE, Flowers ME. Diagnosis and clinical management of chronic graft-versus-host disease. Int $\mathrm{J}$ Hematol. 2004;79(3):221-8.

27. Arora M, Nagaraj S, Wagner JE, Barker JN, Brunstein CG, et al. Chronic graft-versus-host disease (cGVHD) following unrelated donor hematopoietic stem cell transplantation (HSCT): higher response rate in recipients of unrelated donor (URD) umbilical cord blood (UCB). Biol Blood Marrow Transplant. 2007; 13(10):1145-52.

28. Martin PJ, Storer BE, Rowley SD, et al. Evaluation of mycophenolate mofetil for initial treatment of chronic graft-versushost disease. Blood. 2009; 13(21):5074-82.

29. Wang Y, Xu LP, Liu DH, et al. First-line therapy for chronic graftversus-host disease that includes low-dose methotrexate is associated with a high response rate. Biol Blood Marrow Transplant. 2009;15(4):505-11

30. Koc S, Leisenring W, Flowers ME, Anasetti C, Deeg HJ, Nash RA, et al. Thalidomide for treatment of patients with chronic graftversus-host disease. Blood. 2000;96(12):3995-6.

31. Arora M, Wagner JE, Davies SM, et al. Randomized clinical trial of thalidomide, cyclosporine and prednisone versus cyclosporine and prednisone as initial therapy for chronic graft-versus-host disease. Biol Blood Marrow Transplant. 2001;7(5):265-73.

32. Bergeron A, Belle A, Chevret $\mathrm{S}$, et al. Combined inhaled steroids and bronchodilatators in obstructive airway disease after allogeneic stem cell transplantation. Bone Marrow Transplant. 2007;39(9):547-53.

33. Bashoura L, Gupta S, Jain A, et al. Inhaled corticosteroids stabilize constrictive bronchiolitis after hematopoietic stem cell transplantation. Bone Marrow Transplant. 2008;41(1):63-7.

34. Lopez F, Parker P, Nademanee A, et al. Efficacy of mycophenolate mofetil in the treatment of chronic graft-versus-host disease. Biol Blood Marrow Transplant. 2005;11(4):307-13.

35. Baudard M, Vicent A, Moreau P, et al. Mycophenolate mofetil for the treatment of acute and chronic GVHD is effective and well tolerated but induces a high risk of infectious complications: a series of $21 \mathrm{BM}$ or PBSC transplant patients. Bone Marrow Transplant. 2002;30:287-95.

36. Mookerjee B, Altomonte V, Vogelsang G. Salvage therapy for refractory chronic graft-versus-host disease with mycophenolate mofetil and tacrolimus. Bone Marrow Transplant. 1999;24:517-20.

37. Busca A, Locatelli F, Marmont F, Audisio E, Falda M. Response to mycophenolate mofetil therapy in refractory chronic graft-versushost disease. Haematologica. 2003;88:837-9.

38. Flowers ME, Apperley JF, Besien K, et al. A multicenter prospective phase II randomized study of extracorporeal photopheresis for treatment of chronic graft-versus-host disease. Blood. 2008;112 (7):2667-74

39. Couriel DR, Hosing C, Saliba R, et al. Extracorporeal photochemotherapy for the treatment of steroid-resistant chronic GVHD. Blood. 2006;107:3074-80.

40. Apisarnthanarax N, Donato M, Körbling M, et al. Extracorporeal photopheresis therapy in the management of steroid-refractory or steroid-dependent cutaneous chronic graft-versus-host disease after allogeneic stem cell transplantation: feasibility and results. Bone Marrow Transplant. 2003;31(6):459-65.

41. Foss FM, DiVenuti GM, Chin K, et al. Prospective study of extracorporeal photopheresis in steroid-refractory or steroidresistant extensive chronic graft-versus-host disease: analysis of response and survival incorporating prognostic factors. Bone Marrow Transplant 2005;35(12):1187-93. 
42. Carnevale-Schianca F, Martin P, Sullivan K, Flowers M, Gooley T, Anasetti $\mathrm{C}$, et al. Changing from cyclosporine to tacrolimus as salvage therapy for chronic graft-versus-host disease. Biol Blood Marrow Transplant. 2000;6(6):613-20.

43. Tzakis AG, Abu-Elmagd K, Fung JJ, Bloom EJ, Nour B, Greif F, et al. FK 506 rescue in chronic graft-versus-host-disease after bone marrow transplantation. Transplant Proc. 1991;23(6):3225-7.

44. Couriel DR, Saliba R, Escalón MP, Hsu Y, Ghosh S, Ippoliti C, et al. Sirolimus in combination with tacrolimus and corticosteroids for the treatment of resistant chronic graft-versus-host disease. $\mathrm{Br} \mathrm{J}$ Haematol. 2005;130(3):409-17.

45. Johnston LJ, Brown J, Shizuru JA, et al. Rapamycin (sirolimus) for treatment of chronic graft-versus-host disease. Biol Blood Marrow Transplant. 2005;11(1):47-55.

46. Jurado M, Vallejo C, Perez-Simon JA, et al. Sirolimus as part of immunosuppressive therapy for refractory chronic graft-versushost disease. Biol Blood Marrow Transplant 2007;13(6):701-6.

47. Cutler C, Miklos D, Kim HT, et al. Rituximab for steroid-refractory chronic graft-versus-host disease. Blood. 2006;108:756-62.

48. Zaja F, Bacigalupo A, Patriarca F, et al. Treatment of refractory chronic GVHD with rituximab: a GITMO study. Bone Marrow Transplant. 2007;40:273-7.

49. Jacobsohn DA, Chen AR, Zahurak M, et al. Phase II study of pentostatin in patients with corticosteroid-refractory chronic graft-versus-host disease. J Clin Oncol. 2007;25:4255-61.

50. Kulkarni S, Powles R, Sirohi B, et al. Thalidomide after allogeneic haematopoietic stem cell transplantation: activity in chronic but not in acute graft-versus-host disease. Bone Marrow Transplant. 2003;32:165-70.

51. Browne PV, Weisdorf DJ, DeFor T, et al. Response to thalidomide therapy in refractory chronic graft-versus-host disease. Bone Marrow Transplant. 2000;26:865-9.

52. Parker PM, Chao N, Nademanee A, et al. Thalidomide as salvage therapy for chronic graft-versus-host disease. Blood. 1995;86: 3604-9.

53. Hockenbery DM, Cruickshank S, Rodell TC, et al. A randomized, placebo-controlled trial of oral beclomethasone dipropionate as a prednisone-sparing therapy for gastrointestinal graft-versus-host disease. Blood. 2007;109(10):4557-63.

54. Iyer RV, Hahn T, Roy HN, et al. Long-term use of oral beclomethasone dipropionate for the treatment of gastrointestinal graft-versushost disease. Biol Blood Marrow Transplant. 2005;11(8):58792.

55. Giaccone L, Martin P, Carpenter P, et al. Safety and potential efficacy of low-dose methotrexate for treatment of chronic graftversus-host disease. Bone Marrow Transplant. 2005;36:337-41.

56. Inagaki J, Nagatoshi Y, Hatano M, et al. Low-dose MTX for the treatment of acute and chronic graft-versus-host disease in children. Bone Marrow Transplant. 2008;41(6):571-7.

57. Akpek G, Lee SM, Anders V, Vogelsang GB. A high-dose pulse steroid regimen for controlling active chronic graftversus-host disease. Biol Blood Marrow Transplant. 2001;7:495-502.

58. Gilman AL, Chan KW, Mogul A, et al. Hydroxychloroquine for the treatment of chronic graft-versus-host disease. Biol Blood Marrow Transplant. 2000;6(3A):327-34.

59. Willenbacher W, Basara N, Blau IW, et al. Treatment of steroid refractory acute and chronic graft-versus-host disease with daclizumab. Br J Haematol. 2001;112(3):820-3.

60. Chiang KY, Abhyankar S, Bridges K, et al. Recombinant human tumor necrosis factor receptor fusion protein as complementary treatment for chronic graft-versus-host disease. Transplantation. 2002;73:665-7.
61. Magro L, Catteau B, Coiteux V, et al. Efficacy of imatinib mesylate in the treatment of refractory sclerodermatous chronic GVHD. Bone Marrow Transplant. 2008;42(11):757-60.

62. Shapira MY, Abdul-Hai A, Resnick IB, et al. Alefacept treatment for refractory chronic extensive GVHD. Bone Marrow Transplant. 2009;43(4):339-43.

63. Jacobsohn DA. Emerging therapies for graft-versus-host disease. Expert Opin Emerg Drugs. 2003;8(2):323-38.

64. Mayer J, Krejci M, Doubek M, et al. Pulse cyclophosphamide for corticosteroid-refractory graft-versus-host disease. Bone Marrow Transplant. 2005;35(7):699-705.

65. Lee SJ, Wegner SA, McGarigle CJ, et al. Treatment of chronic graftversus-host disease with clofazimine. Blood 1997;89(7):2298-302.

66. Marcellus DC, Altomonte VL, Farmer ER, et al. Etretinate therapy for refractory sclerodermatous chronic graft-versus-host disease. Blood. 1999;93(1):66-70.

67. Andree H, Hilgendorf I, Leithaeuser M, Junghanss C, Holzhueter S, Loddenkemper C, Steiner B, Freund M, Wolff D. Enteral budesonide in treatment for mils and moderate gastrointestinal chronic GVHD. Bone Marrow Transplant. 2008;42(8):541-6.

68. Hori A, Kanda Y, Goyama S, Onishi Y, et al. A prospective trial to evaluate the safety and efficacy of pravastatin for the treatment of refractory chronic graft-versus-host disease. Transplantation. $2005 ; 79(3): 372-4$

69. Ringden O, Uzunel M, Rasmusson I, et al. Mesenchymal stem cells for treatment of therapy-resistant graft-versus-host disease. Transplantation. 2006;81(10):1390-7.

70. Lee SJ. New approaches for preventing and treating chronic graftversus-host disease. Blood. 2005;105(11):4200-6.

71. Shlomchik WD, Lee SJ, Couriel D, Pavletic SD, et al. Transplantation's greatest challenges: advances in chronic graft-versus-host disease. Biol Blood Marrow Transplant. 2007;13(Suppl 1):2-10.

72. Berger M, Biasin E, Saglio F, Fagioli F. Innovative approaches to treat steroid-resistant or steroid refractory GVHD. Bone Marrow Transplant. 2008;42(Suppl 2):S101-5.

73. Kitajima T, Imamura S. Graft-versus-host reaction enhanced by ultraviolet radiation. Arch Dermatol Res. 1993;285(8):499-501.

74. Grundmann-Kollmann M, Martin H, Ludwig R, Klein S, Boehncke WH, Hoelzer D, et al. Narrowband UV-B phototherapy in the treatment of cutaneous graft versus host disease. Transplantation. 2002;74(11):1631-4.

75. Vogelsang GB, Wolff D, Altomonte V, et al. Treatment of chronic graft-versus-host disease with ultraviolet irradiation and psoralen (PUVA). Bone Marrow Transplant. 1996;17(6):1061-7.

76. Bouzas LF. Doença enxerto-contra-hospedeiro crônica em transplante de medula óssea:tratamento com psoraleno e ultravioleta A. Dissertação (Mestrado em Hematologia). Faculdade de Medicina, Universidade Federal do Rio de Janeiro. Rio de Janeiro, 1996.

77. Bouzas LFS, Ferman S, Matta JLR, Tabak DG, Diamond MH, Ornellas MS, et al. Treatment of chronic graft versus host disease with 8methoxypsoralen and ultravioleta. Blood. 1993;82 (suppl 1):420 A.

78. Elad S, Or R, Resnick I, Shapira MY. Topical tacrolimus-a novel treatment alternative for cutaneous chronic graft-versus-host disease. Transpl Int. 2003;16(9):665-70.

79. Ziemer M, Gruhn B, Thiele JJ, Elsner P. Treatment of extensive chronic cutaneous graft-versus-host disease in an infant with topical pimecrolimus. J Am Acad Dermatol. 2004;50(6):946-8.

80. Smith APS, Fife CE. Advanced therapeutics:the biochemistry and biophysical basis of wound products. In: Sheffield PJ ed. Wound Care Practice. Flagstaff AZ: Best Publishing Company; 2004, pp. 685-730. 
81. Couriel DR. Ancillary and supportive care in chronic graft-versushost disease. Best Pract Res Clin Haematol. 2008;21(2):291-307.

82. Epstein JB, Gorsky M, Epstein MS, Nantel S. Topical azathioprine in the treatment of immune-mediated chronic oral inflammatory conditions: a series of cases. Oral Surg Oral Med Oral Pathol Oral Radiol Endod. 2001;91(1):56-61

83. Schubert MM, Correa ME. Oral graft-versus-host disease. Dent Clin North Am. 2008;52(1):79-109, viii-ix.

84. Albert MH, Becker B, Schuster FR, Klein B, Binder V, Adam K, et al. Oral graft vs. host disease in children - treatment with topical tacrolimus ointment. Pediatr Transplant. 2007;11(3):306-11.

85. Al-Hashimi I, Schifter M, Lockhart PB, et al. Oral lichen planus and oral lichenoid lesions: diagnostic and therapeutic considerations. Oral Surg Oral Med Oral Pathol Oral Radiol Endod. 2007;103(Suppl): S25 e21-12.

86. Horwitz ME, Sullivan KM. Chronic graft-versus-host disease. Blood Rev. 2006;20(1):15-27.

87. Eckardt A, Starke O, Stadler M, Reuter C, Hertenstein B. Severe oral chronic graft-versus-host disease following allogeneic bone marrow transplantation: highly effective treatment with topical tacrolimus. Oral Oncol. 2004;40(8):811-4.

88. Wolff D, Anders V, Corio R, et al. Oral PUVA and topical steroids for treatment of oral manifestations of chronic graft-vs.-host disease. Photodermatol Photoimmunol Photomed. 2004;20(4):184-90.

89. Sanchez AR, Sheridan PJ, Rogers RS. Successful treatment of oral lichen planus-like chronic graft-versus-host disease with topical tacrolimus: a case report. J Periodontol. 2004;75(4):613-9.

90. Elad S, Or R, Resnick I, Shapira MY. Topical tacrolimus - a novel treatment alternative for cutaneous chronic graft-versus-host disease. Transpl Int. 2003;16(9):665-70

91. Epstein JB, Nantel S, Sheoltch SM. Topical azathioprine in the combined treatment of chronic oral graft-versus-host disease. Bone Marrow Transplant. 2000;25(6):683-7.

92. Epstein JB, Truelove EL. Topical cyclosporine in a bioadhesive for treatment of oral lichenoid mucosal reactions: an open label clinical trial. Oral Surg Oral Med Oral Pathol Oral Radiol Endod. 1996;82(5):532-6.

93. Bertz H, Afting M, Kreisel W, Duffner U, Greinwald R, Finke J. Feasibility and response to budesonide as topical corticosteroid therapy for acute intestinal GVHD. Bone Marrow Transplant. 1999;24(11):1185-9.

94. Schubert MM, Sullivan KM: Recognition, incidence, and management of oral graft-versus-host disease. NCI Monogr: 1990:135-43

95. Calissendorff B, el Azazi M, Lönnqvist B. Dry eye syndrome in long-term follow-up of bone marrow transplanted patients. Bone Marrow Transplant. 1989;4(6):675-8.

96. Jack MK, Jack GM, Sale GE, Shulman HM, Sullivan KM. Ocular manifestations of graft-v-host disease. Arch Ophthalmol. 1983; 101(7):1080-4

97. Hill JC. Slow-release artificial tear inserts in the treatment of dry eyes in patients with rheumatoid arthritis. $\mathrm{Br} \mathrm{J}$ Ophthalmol. 1989;73(2):151-4

98. Peral A, Domínguez-Godínez CO, Carracedo G, Pintor J. Therapeutic targets in dry eye syndrome. Drug News Perspect. 2008;21(3):16676. Review.

99. Cosar CB, Cohen EJ, Rapuano CJ, Maus M, Penne RP, Flanagan JC, Laibson PR. Tarsorrhaphy: clinical experience from a cornea practice. Cornea. 2001;20(8):787-91.

100. Punctal occlusion for the dry eye. Three-year revision. American Academy of Ophthalmology. Ophthalmology. 1997;104(9): $1521-4$.
101. Marsh P, Pflugfelder SC. Topical nonpreserved methylprednisolone therapy for keratoconjunctivitis sicca in Sjögren syndrome. Ophthalmology. 1999;106(4):811-6.

102. Sall K, Stevenson OD, Mundorf TK, Reis BL. Two multicenter, randomized studies of the efficacy and safety of cyclosporine ophthalmic emulsion in moderate to severe dry eye disease. CsA Phase 3 Study Group. Ophthalmology. 2000;107(4):631-9.

103. Wang Y, Ogawa Y, Dogru M, Kawai M, Tatematsu Y, Uchino M, et al.Ocular surface and tear functions after topical cyclosporine treatment in dry eye patients with chronic graft-versus-host disease. Transplant. 2008;41(3):293-302.

104. De Paiva CS, Corrales RM, Villarreal AL, Farley W, Li DQ, Stern $\mathrm{ME}$, et al. Apical corneal barrier disruption in experimental murine dry eye is abrogated by methylprednisolone and doxycycline. Invest Ophthalmol Vis Sci. 2006;47(7):2847-56.

105. Quinto GG, Campos M, Behrens A. Autologous serum for ocular surface diseases. Arq Bras Oftalmol. 2008;71(6 Suppl):47-54.

106. Kojima T, Ishida R, Dogru M, Goto E, Matsumoto Y, Kaido M, et $a l$. Theeffect of autologous serum eyedrops in the treatment of severe dry eye disease: a prospective randomized case-control study. Am J Ophthalmol. 2005;139(2):242-6.

107. Ogawa Y, Okamoto S, Mori T, Yamada M, Mashima Y, Watanabe $\mathrm{R}$, et al. Autologous serum eye drops for the treatment of severe dry eye in patients with chronic graft-versus-host disease. Bone Marrow Transplant.2003;31(7):579-83.

108. Tsubota K, Goto E, Shimmura S et al. Treatment of persistent corneal epithelial defect by autologous serum application. Ophthalmology 1999;106(10):1984-9.

109. van Setten GB, Viinikka L, Tervo T, Pesonen K, Tarkkanen A, Perheentupa $\mathrm{J}$, et al. Epidermal growth factor is a constant component of normal human tear fluid. Graefe's Arch Clin Exp Ophthalmol. 1989;227(2):184-7.

110. Ogawa Y, Okamoto S, Mori T, et al. Autologous serum eye drops for the treatment of severe dry eye in patients with chronic graftversus-host disease. Bone Marrow Transplant. 2003;31:579-83.

111. Leite SC, de Castro RS, Alves M, Cunha DA, Correa ME, da Silveira LA, et al. Risk factors and characteristics of ocular complications, and efficacy of autologous serum tears after haematopoietic progenitor cell transplantation. Bone Marrow Transplant. 2006;38(3):223-7.

112. Corson SL, Sullivan K, Batzer F, August C, Storb R, Thomas ED. Gynecologic manifestations of chronic graft-versus-host disease. Obstet Gynecol. 1982;60(4):488-92.

113. Schubert MA, Sullivan KM, Schubert MM, Nims J, Hansen M, Sanders JE, et al. Gynecological abnormalities following allogeneic bone marrow transplantation. Bone Marrow Transplant. 1990;5 (6):425-30.

Este artigo foi avaliado pelos coordenadores das Diretrizes do Transplante de Medula Óssea da Sociedade Brasileira de Transplante de Medula Óssea, Luis Fernando Bouzas, Prof. Julio Cesar Voltarelli e Nelson Hamerschlak, e publicado após avaliação e revisão do editor, Milton Artur Ruiz

Conflito de interesse: sem conflito de interesse

Recebido: 20/08/2009

Aceito: 05/10/2009 